\title{
Genomics of Three New Bacteriophages Useful in the Biocontrol of Salmonella
}

\section{Carlota Bardina ${ }^{\dagger}$, Joan Colom ${ }^{\dagger}$, Denis A. Spricigo ${ }^{\dagger}$, Jennifer Otero, Miquel Sánchez-Osuna, Pilar Cortés * and Montserrat Llagostera}

Departament de Genètica i de Microbiologia, Molecular Microbiology, Universitat Autònoma de Barcelona, Barcelona, Spain

\section{OPEN ACCESS}

Edited by:

Pilar García,

Consejo Superior de Investigaciones Cientificas, Spain

Reviewed by:

M. Rosario Rodicio, University of Oviedo, Spain

Sívio B. Santos,

University of Minho, Portugal Sherwood Reid Casjens,

University of Utah, USA

*Correspondence: Pilar Cortés

mariapilar.cortes@uab.cat

${ }^{\dagger}$ These authors have contributed equally to this work.

Specialty section: This article was submitted to Antimicrobials, Resistance and

Chemotherapy,

a section of the journal

Frontiers in Microbiology

Received: 28 January 2016 Accepted: 04 April 2016

Published: 20 April 2016

Citation:

Bardina C, Colom J, Spricigo DA, Otero J, Sánchez-Osuna M, Cortés $P$ and Llagostera M (2016) Genomics of

Three New Bacteriophages Useful in the Biocontrol of Salmonella.

Front. Microbiol. 7:545.

doi: 10.3389/fmicb.2016.00545
Non-typhoid Salmonella is the principal pathogen related to food-borne diseases throughout the world. Widespread antibiotic resistance has adversely affected human health and has encouraged the search for alternative antimicrobial agents. The advances in bacteriophage therapy highlight their use in controlling a broad spectrum of food-borne pathogens. One requirement for the use of bacteriophages as antibacterials is the characterization of their genomes. In this work, complete genome sequencing and molecular analyses were carried out for three new virulent Salmonella-specific bacteriophages (UAB_Phi20, UAB_Phi78, and UAB_Phi87) able to infect a broad range of Salmonella strains. Sequence analysis of the genomes of UAB_Phi20, UAB_Phi78, and UAB_Phi87 bacteriophages did not evidence the presence of known virulence-associated and antibiotic resistance genes, and potential immunoreactive food allergens. The UAB_Phi20 genome comprised 41,809 base pairs with 80 open reading frames (ORFs); 24 of them with assigned function. Genome sequence showed a high homology of UAB_Phi20 with Salmonella bacteriophage P22 and other P22likeviruses genus of the Podoviridae family, including ST64T and ST104. The DNA of UAB_Phi78 contained 44,110 bp including direct terminal repeats (DTR) of 179 bp and 58 putative ORFs were predicted and 20 were assigned function. This bacteriophage was assigned to the SP6likeviruses genus of the Podoviridae family based on its high similarity not only with SP6 but also with the K1-5, K1E, and K1F bacteriophages, all of which infect Escherichia coli. The UAB_Phi87 genome sequence consisted of 87,669 bp with terminal direct repeats of $608 \mathrm{bp}$; although 148 ORFs were identified, putative functions could be assigned to only 29 of them. Sequence comparisons revealed the mosaic structure of UAB_Phi87 and its high similarity with bacteriophages Felix 01 and wV8 of E. coli with respect to genetic content and functional organization. Phylogenetic analysis of large terminase subunits confirms their packaging strategies and grouping to the different phage genus type. All these studies are necessary for the development and the use of an efficient cocktail with commercial applications in bacteriophage therapy against Salmonella.

Keywords: Salmonella, bacteriophage, genomics, chromosomal ends, Myoviridae, Podoviridae 


\section{INTRODUCTION}

Non-typhoid Salmonella is the leading reported pathogen related to food-borne diseases, both in the European Union (EU) (European Food Safety Authority and European Centre for Disease Prevention Control, 2014) and in the USA (CDC, 2011). Salmonellosis in humans is often related to the ingestion of contaminated animal products (poultry, swine, beef, etc.) or of fruits and vegetables contaminated by animal waste (European Food Safety Authority and European Centre for Disease Prevention Control, 2014), consistent with the prevalence of certain serovars of Salmonella enterica in farm animals (e.g., Typhimurium and Enteritidis). The widespread antibiotic resistance in bacteria from various sources has had adverse effects on human health and has therefore encouraged the search for alternative antimicrobial agents (Endersen et al., 2014).

The natural biotherapeutic potential of bacteriophages is well recognized. Since 2006, different bacteriophage products have been assayed for use as therapeutics and food safety agents (Sulakvelidze, 2011). Bacteriophages and their derivatives are promising resources for use at each stage of the farm-to-fork. Recently, it has been reviewed their use for controlling of several major and emerging food-borne pathogens in both preharvest (farm animals) and postharvest (meat, fresh, and packaged foods) environments (Goodridge and Bisha, 2011). These studies reinforce the commercially exploiting of bacteriophages to diminish the economic weight of microbial contamination in foods and food processing environments.

To date, there is no evidence that bacteriophages exhibit harmful effects on humans or animals (Abedon et al., 2011). They are the most abundant entities and are present in all environments where a suitable host is found due to their high degree of host specificity (Kropinski et al., 2007). Nowadays, a security measure in the use of bacteriophages as antibacterials is that they must undergo whole-genome sequencing to ensure that the genome is free of genes encoding known bacterial virulence factors and potential immunoreactive allergens. Moreover, sequencing helps to understand the multiplicative cycle of bacteriophages at molecular level, and also other important biological traits. With this aim, the present work reports the sequencing and detailed analysis of the genomes of three Salmonella-specific bacteriophages (UAB_Phi20, UAB_Phi78, and UAB_Phi87) and the identification of the type of their genome ends. All three bacteriophages are able to infect not only a broad range of different strains of $S$. Typhimurium and $S$. Enteritidis serovars but also strains of the serovars Virchow, Hadar, and Infantis. They were previously selected from a collection of 55 bacteriophages isolated in poultry and pig feces obtained at different farms in Spain (Cortés et al., 2015). These bacteriophages are efficient against $S$. Typhimurium, both in poultry (Bardina et al., 2012; Colom et al., 2015) and in different food matrices (Spricigo et al., 2013).

\section{MATERIALS AND METHODS}

\section{Bacteriophages}

The three bacteriophages studied in this work, UAB_Phi20, UAB_Phi78, and UAB_Phi87, belong to a collection of 55 bacteriophages previously obtained from 189 chicken cloacae and pig rectal swabs collected from farms in different geographical areas of Spain between 2007 and 2009 (Cortés et al., 2015).

\section{Bacteriophage DNA Extraction}

High-titer $\left(10^{11}-10^{12} \mathrm{pfu} / \mathrm{ml}\right.$ in $\left.\mathrm{MgSO}_{4} 10 \mathrm{mM}\right)$ lysates were obtained from each bacteriophage propagated in $S$. Typhimurium LB5000 strain (SGSC181; University of Calgary) and by ultracentrifugation at $51,000 \times \mathrm{g}$ for $2 \mathrm{~h}\left(\right.$ Optima ${ }^{\mathrm{TM}} \mathrm{L}-80$; Beckman, CA, USA) (Sambrook et al., 1989). Bacteriophage DNA was isolated using a phenol-chloroform method (Sambrook et al., 1989) with slight modifications. Phage suspensions were treated with DNase I ( $80 \mathrm{U} / \mathrm{ml}$; Roche Diagnostics GmbH, Germany) and RNase I ( $80 \mu \mathrm{g} / \mathrm{ml}$; Roche Diagnostics GmbH, Germany) at $37^{\circ} \mathrm{C}$ for $2 \mathrm{~h}$. Following the addition of $0.5 \%$ sodium dodecyl sulfate (SDS, Sigma-Aldrich, St. Louis, MO, USA) and $200 \mu \mathrm{g}$ proteinase K (Roche Diagnostics $\mathrm{GmbH}$, Germany)/ml, they were incubated at $56^{\circ} \mathrm{C}$ for $2 \mathrm{~h}$. Phage DNA was then extracted using phenol:chloroform and precipitated with ethanol. DNA integrity was checked by using a $0.7 \%$ agarose gel electrophoresis stained with Red Safe 1X (Intron Biotechnology; Seongnam-Si, Korea); the concentration was determined in a NanoDrop ND 1000 instrument (Thermo Scientific, DE, USA).

\section{Bacteriophage DNA Sequencing and Genomic Analysis}

The genomes of UAB_Phi20 and UAB_Phi78 were sequenced using the shotgun-full sequencing strategy. The UAB_Phi87 genome was sequenced using the Roche GS FLX system. All sequencing and sequence assembly procedures were done at Sistemas Genómicos (Valencia, Spain).

DNA sequences were analyzed using the software package DNAStar (DNAStar Inc.) and the online databases: http://www. ncbi.nlm.nih, http://www.ebi.ac.uk/, and http://cmr.jcvi.org. The whole-genome sequences of bacteriophages UAB_Phi20, UAB_Phi78, and UAB_Phi87 were deposited at GenBank under accession numbers GQ422450, GU595417, and JN225449, respectively. Possible open reading frames (ORFs) were predicted using the ORF Finder program (http://www.ncbi.nlm.nih.gov/ gorf/gorf.html). ORFs > 25 amino acids in length were further analyzed. Putative functions of ORFs were identified using the alignment search tools (BLASTP, BLASTX, and BLASTN search) of the National Center for Biotechnology Information (NCBI). ATG, GTG, and TTG were considered as start codons and TAA, TGA, and TAG as stop codons. Potential promoter regions and transcription terminators were predicted using the Softberry programs BProm (http://linuxl.softberry.com/ berry.phtml), FindTerm (Solovyev and Salamov, 2011), and TransTerm (Ermolaeva et al., 2000). The presence of a putative Shine-Dalgarno sequence (ribosome binding site, RBS) was confirmed based on its similarity to the Escherichia coli consensus sequence GGAGGT (Shine and Dalgarno, 1974). The tRNAscanSE 1.21 program was used to search putative tRNAs (Lowe and Eddy, 1997). BLASTX and BLASTP were used to search for similarities with proteins in the database (Altschul et al., 1990). MAUVE (Darling et al., 2010) or ClustalW2 (McWilliam et al., 2013) were used for genome comparisons at the nucleotide level based on the genomic sequences available at NCBI (www.ncbi. 
nlm.nih.gov). Comparisons at the proteomic level were made using CoreGenes (Turner et al., 2013). Phylogenetic analysis of phage large terminase subunit sequences was performed by using the ClustalW program in MEGA6 (Tamura et al., 2013). The tree based on neighbor-joining method was generated from a multiple alignment (gap opening penalty, 10; gap extension penalty, 1; and gap separation distance, 0 ). In order to obtain the tree, the parameters were set as following: (i) the model/method was set as number of differences; (ii) gaps/missing data treatment was established as complete deletion, and (iii) the random number generator seed and bootstrap trails were set at 111 and 1000, respectively (Casjens et al., 2005). Finally, the condensed tree was displayed with a bootstrap cut-off value of $70 \%$.

\section{Determination of the Bacteriophage Genome Ends}

To identify potential cos ends, purified DNA of the three phages was digested with EcoRV restriction endonuclease (New England Biolabs, Hitchin, UK) at $37^{\circ} \mathrm{C}$ for $14 \mathrm{~h}$. Two aliquots were then prepared. One was incubated at $60^{\circ} \mathrm{C}$ for $10 \mathrm{~min}$ to separate potentially ligated cos sites and immediately stored on ice. Restriction fragments length polymorphism patterns of heated and non heated aliquots were visualized by agarose gel electrophoresis (0.8\%). Lambda bacteriophage DNA (Roche Diagnostics $\mathrm{GmbH}$, Germany) with cohesive ends and treated with the same methodology served as a control.

On the other hand, the DNA from UAB_Phi20 was digested with EcoRI enzyme (New England Biolabs, Hitchin, UK) to detect an under-represented fragment as indicative of circularly permuted direct terminal repeats (DTR) in the chromosome ends. DNA of P22 bacteriophage was used as a control. Finally, to determine if the chromosome ends of UAB_Phi78 and UAB_Phi87 bacteriophages contain DTR, their DNA was treated with exonuclease Bal31, as described elsewhere (Klumpp et al., 2008). Briefly, $30 \mu \mathrm{g}$ of bacteriophage DNA was treated with Bal31 nuclease (Takara; Saint-Germain-en-Laye, France) (0.5 units $/ \mu \mathrm{g})$ at $30^{\circ} \mathrm{C}$ for different incubation times. The reaction was stopped by the addition of $10 \mu \mathrm{l}$ of EDTA $(20 \mathrm{mM})$ followed by heating at $65^{\circ} \mathrm{C}$ for $5 \mathrm{~min}$. DNA was purified using phenol-chloroform extraction and ethanol precipitation (Sambrook et al., 1989). Purified DNA $(1 \mu \mathrm{g})$ was digested with HindIII (UAB_Phi78) and SpeI (UAB_Phi87) restriction enzymes (New England Biolabs, Hitchin, UK) and analyzed by agarose gel electrophoresis (1\%). Those fragments that disappeared were newly isolated and purified (GE Healthcare Ltd., UK). In silico restriction of UAB_Phi78 and UAB_Phi87 with the adequate cutting sites were performed in order to identify the sequence of the disappeared fragments. In attention to these results, different primers were designed for sequencing the recovered and purified fragments. Finally, the sequences of DTR for both phages were confirmed by sequencing. To do this, the phage genomes were used as templates with primers that previously displayed drop-offs in the sequencing of the recovered fragments.

\section{Isolation of UAB_Phi20 Lysogens}

The possible lysogens present in the clear plaques of bacteriophage UAB_Phi20 on S. Typhimurium ATCC 14028 were picked from 10 plaques and streaked on green plates (Chan et al., 1972). Forty colonies were selected from these plates and streaked on green plates several times until they did not show dark green color. Overnight cultures in LB liquid medium of each colony were obtained and subcultured until an optical density at $550 \mathrm{~nm}\left(\mathrm{OD}_{550}\right)$ of 1.0 was reached. Following, 0.5 $\mu \mathrm{g} / \mathrm{ml}$ of mitomycin C (Sigma, St. Louis, MO) was added to the cultures and incubated at $37^{\circ} \mathrm{C}$ for $2 \mathrm{~h}$. At that time, cultures were centrifuged and filtrated. A spotting assay of the supernatants with S. Typhimurium ATCC 14028 was conducted to ascertain the presence of induced UAB_Phi20. Similarly, a spotting assay of supernatants of overnight cultures was done.

\section{RESULTS AND DISCUSSION}

The adsorption kinetics and the lytic cycle of bacteriophages UAB_Phi20, UAB_Phi78, and UAB_Phi87 used as a cocktail in therapy strategies against $S$. Typhimurium (Bardina et al., 2012; Spricigo et al., 2013; Colom et al., 2015) were previously characterized. They exhibited similar adsorption constant $(\mathrm{K})$ ranging between $1.1 \times 10^{-9}$ and $1.2 \times 10^{-9} \mathrm{ml} \mathrm{cfu}^{-1} \mathrm{~min}^{-1}$ and the timing of the latent period of bacteriophages UAB_Phi20, UAB_Phi78, and UAB_Phi87 was 46.0, 26.7, and $58.0 \mathrm{~min}$, respectively (Bardina, 2011; Spricigo, 2011). The burst sizes of UAB_Phi20 and UAB_Phi78 were similar (95.0 and 87.7 $\mathrm{pfu} / \mathrm{cfu}$, respectively) while that of UAB_Phi87 was $55 \mathrm{pfu} / \mathrm{cfu}$ (Bardina, 2011; Spricigo, 2011). In addition, they were previously characterized with respect to broad host range, restriction patterns, RAPD profiles, morphology, genome size and lytic activity in vitro (Bardina et al., 2012; Cortés et al., 2015).

In this study, we report the whole genome sequencing and some traits of their biology at molecular level. In silico analyses of bacteriophage genomes did not show any similarities neither to known virulence-associated genes nor to any antibiotic resistance genes or potential immunoreactive food allergens (FARRP, 2011). It must be noted that a high percentage of hypothetical proteins were found in their genomes. This agrees with the reported for all sequenced bacteriophages which has been widely commented by the scientific community (Klumpp et al., 2013). Therefore, the identification of their function is a challenge that must be addressed for increasing the knowledge of the bacteriophages and the level of security of their applications. In this regard, it must be considered that none of hypothetical proteins showed significant similarity to known or hypothetical factors involved in bacterial pathogenicity. Therefore, it is unlikely that they have a role in bacterial virulence. Additionally, in our reported in vivo experiments (Bardina et al., 2012), we inoculated the phage cocktail, with and without their host, and no harmful signs were observed in animals. In attention to the above indicated, and given the large amount of information available in bacterial gene databases, the three phages studied are safe with respect to our current knowledge.

\section{Genome Analysis of UAB_Phi20}

The genome of UAB_Phi20 consisted of linear double-stranded DNA (ds DNA), 41,809 base pairs (bp) in length and with an overall genomic guanine plus cytosine $(\mathrm{G}+\mathrm{C})$ content of 
$47.2 \%$ which is slightly lower than its host (52.2\%). ORF Finder revealed 80 possible ORFs. The annotation and organization of the UAB_Phi20 genome are provided in Table 1. Given the high level of genome compaction, many of the promoters identified in UAB_Phi20 overlapped in their coding regions. Therefore, potential promoters were sought using the BPROM program (Softberry), limiting the search to a maximum distance of 100 bp relative to the start of the potential UAB_Phi20 phage genes. All 12 hypothetical promoters thus identified (Table S1) had a highly conserved -10 consensus sequence (TATAAT), while in the -35 box (TTGACA) only the second $T$ and the $G$ were strongly conserved. In addition, there were 11 putative Rho-independent terminators (Figure 1). ATG was the start codon in all ORFs except gene p80, in which TTG was the start codon. The three stop codons were present in different proportions, with TAA as the most common $(56.3 \%$ of the genes), followed by TGA and TAG (in 36.2 and $7.5 \%$ of the ORFs, respectively). The RBS Finder (Glimmer) program revealed partial conservation of the ribosome-binding sites (RBS) of bacteriophage UAB_Phi20 with respect to the ShineDalgarno consensus sequence (AGGAGG). Interestingly, the distance of this sequence from the translation initiation site was not conserved in all genes but instead ranged from only 7 to $40 \mathrm{bp}$.

The genomic annotation and the analysis of the genetic organization of phage UAB_Phi20 showed high homology with that of Salmonella bacteriophage P22 and other P22likevirus. Functions were assigned to 42 ORFs of the 80 identified (Table 1). In addition, 14 ORFs corresponded to $e a$ and nin regions. Of the remaining 24 ORFs, 16 encoded proteins which showed similarity with hypothetical proteins already described, but their functions could not be determined, and 8 ORFs showed no similarity with any protein available in the databases. The proteins of UAB_Phi20 were classified into different functional groups (Figure 1).

The lysogeny group included proteins involved on the establishment of lysogeny, lysogenic conversion, immunity, the excisionase and the attP region. The establishment of lysogeny requires the activity of the integrase encoded by int gene. This protein showed an identity $\geq 98 \%$ compared to the counterparts in bacteriophages P22, ST64T, and ST104. A hypothetical attP site with a sequence similar to that described in P22 was also found between the genes int and gtrA. The products of the genes $c 2$, cro, $c 1$, and $c 3$ genes, which directly affect phage decision between lytic or lysogenic cycle, and those encoded by $m n t$, arc, and ant genes, which are involved in the control of the maintenance of lysogeny (Susskind and Botstein, 1978) showed a high similarity with those of P22. During lysogenic conversion, the lysogenization of bacterial cells with certain lambdoid bacteriophages produces a chemical change in the bacterial lipopolysaccharide $\mathrm{O}$ antigen such that the binding of other bacteriophages that recognize the same receptor is prevented (Kropinski et al., 2007). The UAB_Phi20 genes that are responsible for this function are $g \operatorname{tr} C, g \operatorname{tr} B$, and $g \operatorname{tr} A$; all of their products showed $\geq 99 \%$ homology with their counterparts in bacteriophages P22, ST64T, and ST104. The genome of
UAB_Phi20 also contains three genes (17, sieA, and sieB) encoding proteins involved in the exclusion of superinfection (immunity). These proteins were very similar to those of phage P22. Protein 17 participates in the release of exclusion by heterologous phages such as Fels-1, whereas SieB and SieA prevent infection by heteroimmune phages or superinfection by the own phage (Susskind and Botstein, 1978). In addition, the excisionase (xis) showed an identity of $100 \%$ compared to the corresponding protein in P22 and ST64T, whereas for ST104 the identity was $\sim 97 \%$.

The gene products involved in the DNA metabolism of UAB_Phi20 were identical to those of ST104 but had only $\sim 70 \%$ identity with those of phage P22. This group of genes included $a b c 2$ and $a b c 1$, encoding a protein with an antiRecBCD function, and the hypothetical erf and arf genes, involved in the recombination and recircularization of phage DNA (Poteete et al., 1988). Genome replication by UAB_Phi20 requires two proteins similar to the helicase $(\mathrm{Gp} 12)$ and primase (Gp18) proteins of P22 (Vander Byl and Kropinski, 2000).

A cluster of UAB_Phi20 genes involved in the bacterial lysis encoding holin ( $g p 13)$, lysozyme ( $g p 19)$, and two endopeptidases ( $g p 15$ and $R z 1$ ) were identified. All these proteins were identical to those of phage P22. After the endopeptidases, the orf21, which may also play a role in bacterial lysis, was identified. However, as no gene homologous to orf 21 was found in the databases, neither its function nor its assignment to the lysis region could be confirmed.

Genes involved in structure and assembly could be divided into those encoding terminases, capsid, DNA injection, or tail proteins. The major part of proteins involved in these functions was similar to the respective proteins of phage P22 and presented a high identity with those encoded by bacteriophages ST104 and ST64T. For example, UAB_Phi20 tail-spike and the major capsid proteins were almost identical $(\geq 99 \%)$ to the respective proteins of bacteriophages P22, ST104 and ST64T. Both the small and large terminases, encoded by $g p 3$ and $g p 2$, respectively, had an identity of $\sim 100 \%$ with the genes of P22, ST104, and ST64T phages. In a recent work comparing 57 P22-like bacteriophages (Casjens and Thuman-Commike, 2011), terminases and capsid proteins were the most conserved, whereas the most divergent proteins were related to host recognition, such as tail and injection proteins. However, the high identity found by us for all these proteins indicates a low divergence and strong phylogenetic relationship between UAB_Phi20 and bacteriophages P22, ST104, and ST64T. In addition, the genome of UAB_Phi20 contained a unique site ( $p a c$ ) located within the sequence of the small subunit of terminase. $\mathrm{Pac}$ sequence (GAAGACTTATCTGAGGTCGTTA) differed by two bases from the corresponding sequence of P22 ( Wu et al., 2002).

Besides regions above commented, other important feature of the UAB_Phi20 genome was the identification of ea and nin regions, which encoded a number of proteins of unknown function. Neither of these genes is essential for bacteriophage function, at least in in vitro cultures, but their presence and maintenance suggest that they confer a selective advantage for 
TABLE 1 | Features of bacteriophage UAB_Phi20 genome, ORFs, gene products, and functional assignments.

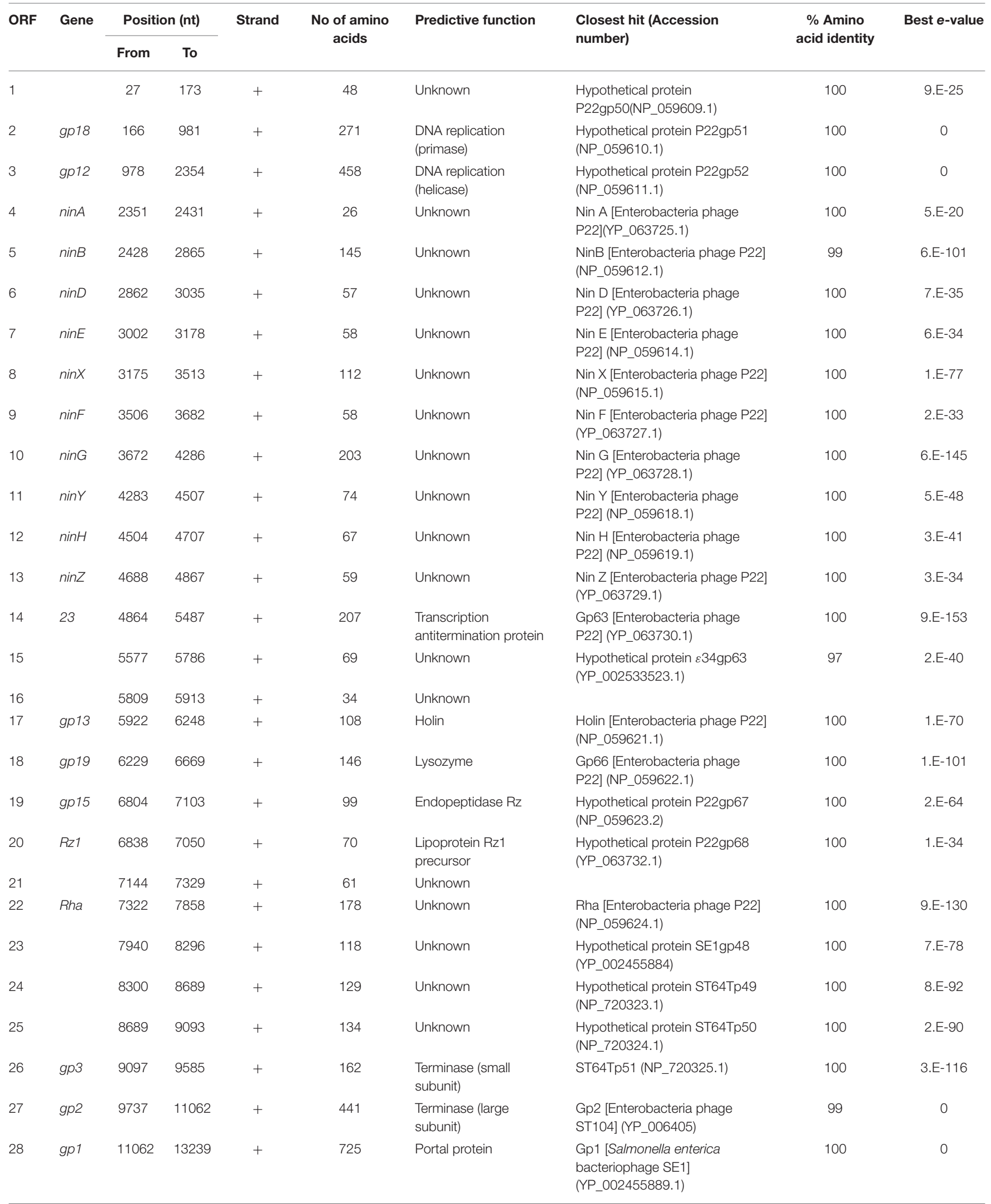


TABLE 1 | Continued

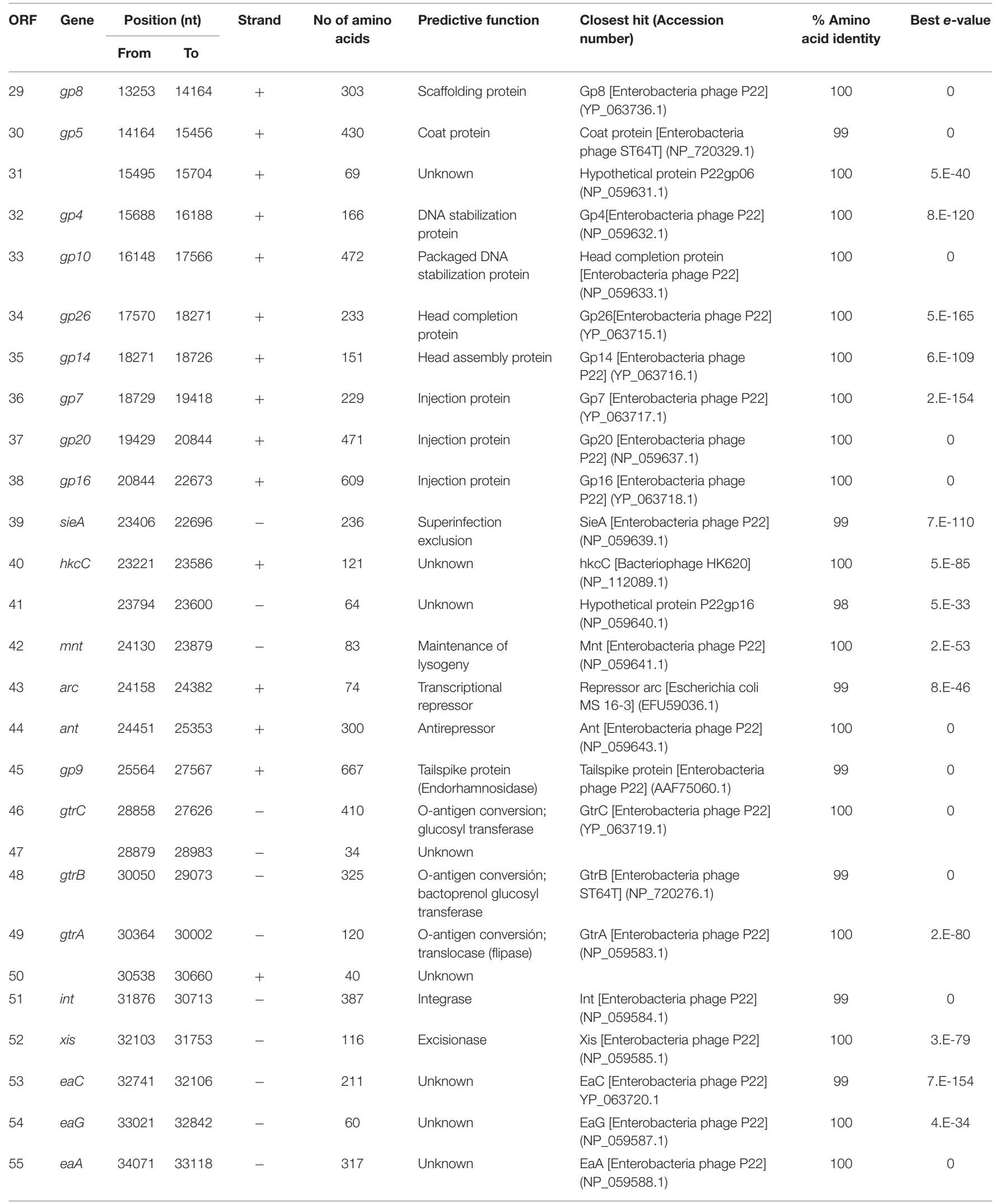


TABLE 1 | Continued

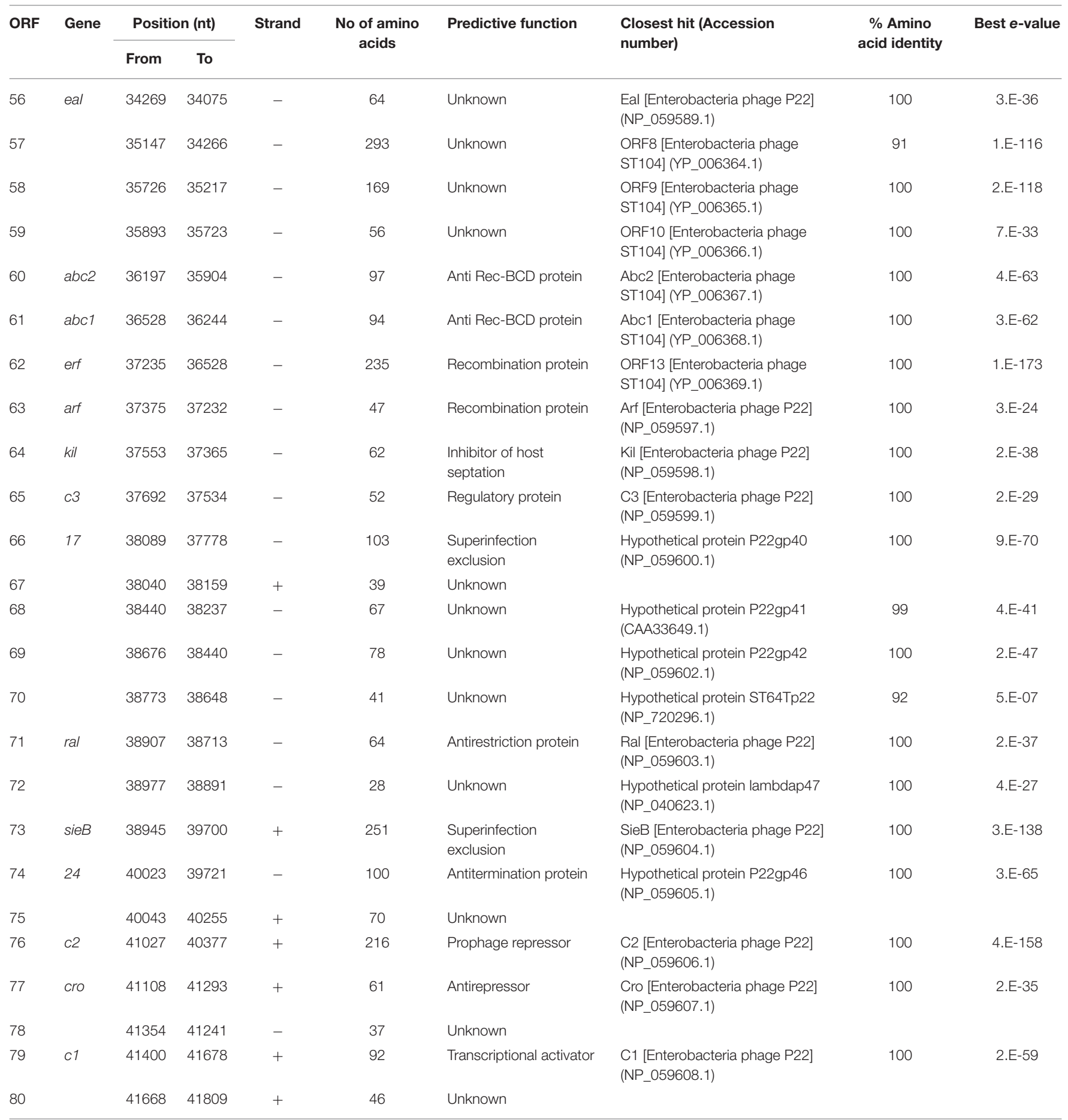

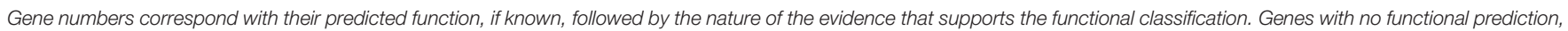
but with significant sequence similarity to genes in the NCBI database as determined by BLASTP are also listed.

either the host or the bacteriophage itself when present in other environments (Hendrix, 2002).

Although the UAB_Phi20 genome contains all the elements for giving a lysogenic cycle, infected-Salmonella cultures by this bacteriophage were completely cleared and UAB_Phi20 plaques were also typically clear. Both observations suggested that this phage is virulent and unable to promote a lysogenic cycle. The possible reasons of this apparent contradiction were studied. First of all we considered that the hypothetical attP sequence of UAB_Phi20 is similar to that described in P22 bacteriophage. 


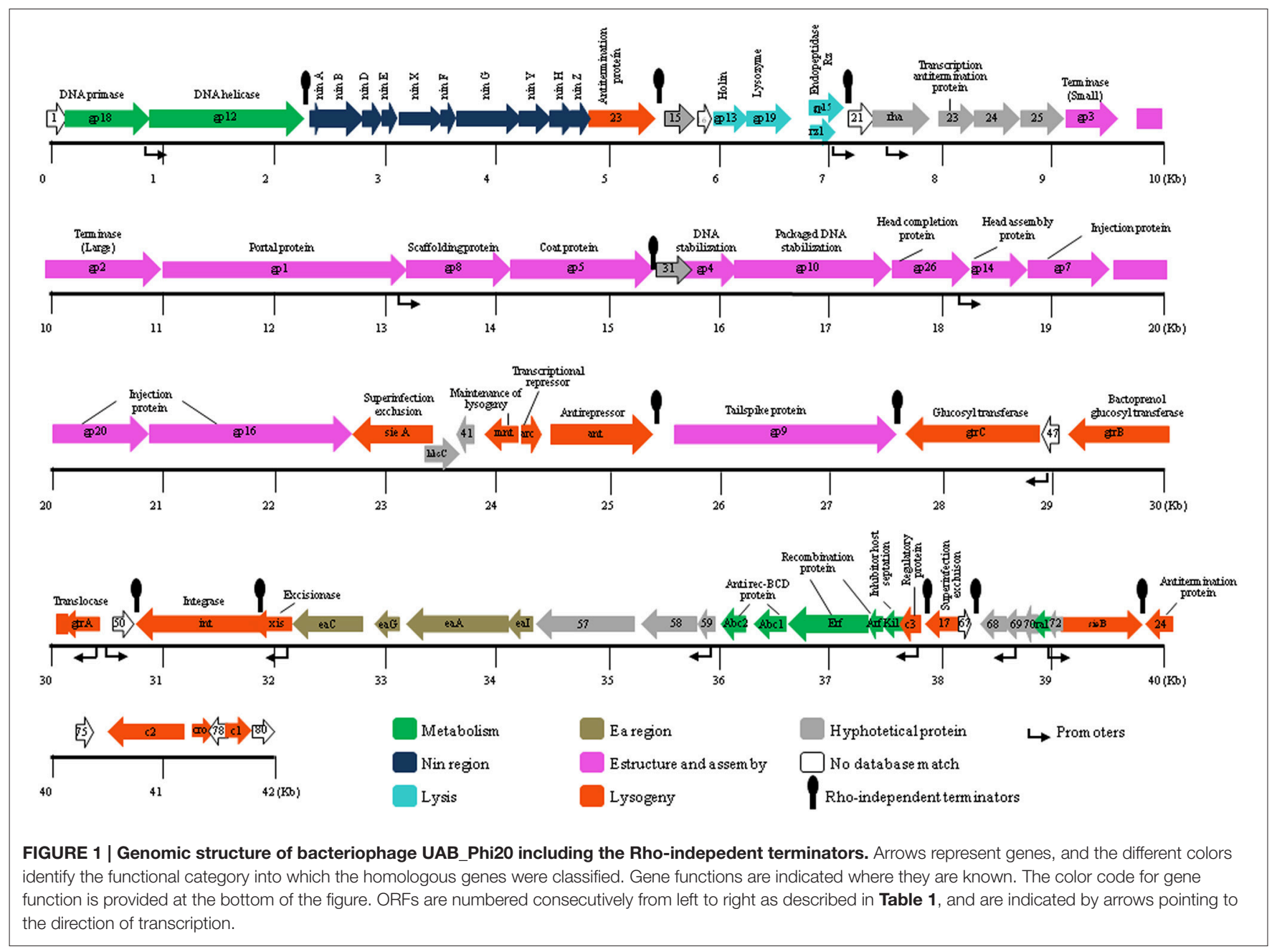

Therefore, bacteriophage UAB_Phi20 could integrate into the P22 site (attB) of the Salmonella chromosome (Smith-Mungo et al., 1994). However, we were unable to detect this by PCR amplification studies (data not shown). In addition, the possible C1 recognition motif (TTGN6TTGC) in the UAB_Phi20 genome was not identified neither at the region of the $\mathrm{P}_{R E}$ promoter nor in the vicinity of the gene encoding integrase and, as consequence, the repressor of the lytic cycle cannot be transcribed. However, these data did not discard that UAB_Phi20 had a very low frequency of lysogenization which could result in apparently clear plaques. To test this, the possible lysogens present in the clear plaques were picked and streaked on green plates. Afterwards, 40 colonies were selected from these plates and, for removing the possible bacteriophages coming from plaques, they were streaked on green plates until they did not show dark green color. If UAB_Phi20 had a low frequency of lysogenization, it would be expected that some of these colonies were stable lysogens. However, the treatment of liquid cultures of those colonies with mitomycin $\mathrm{C}$ did not yield bacteriophage production. In addition, no bacteriophages were detected in the supernatant of overnight cultures of these colonies. All these results evidenced that the bacteriophage UAB_Phi20 is unable to give rise a lysogenic cycle producing stable lysogens on this host.

Comparison of the genome of UAB_Phi20 with those of P22, ST64T, and ST104 at protein level using CoreGenes (Turner et al., 2013) revealed that shared $72 \%$ of its proteins with P22 and $63-65 \%$ with those of ST64T, and ST104. These results agree with that obtained by BlastP with protein-by-protein comparison (Table 1) and allow classifying UAB_Phi20 into P22likevirus genus as sharing at least $40 \%$ of proteins is a requisite to be classified into a determined genus (Lavigne et al., 2008). Finally, alignment of the annotated genomes of these bacteriophages using Mauve demonstrated the considerable sequence similarity between UAB_Phi20 and P22. Few noticeable differences with respect to ST64T and ST104 bacteriophages, especially at region $34-40 \mathrm{~kb}$ on the UAB_Phi20 genome, were observed (Figure 2). The high similarities between their genes, their organization and the identification of hypothetical genes lacking similarity with the above-mentioned bacteriophages demonstrate the genome mosaicism of these members of the Podoviridae. The origin of this genetic mosaicism agrees with the model of modular evolution of bacteriophages in which the horizontal transfer of genetic modules and their incorporation by 


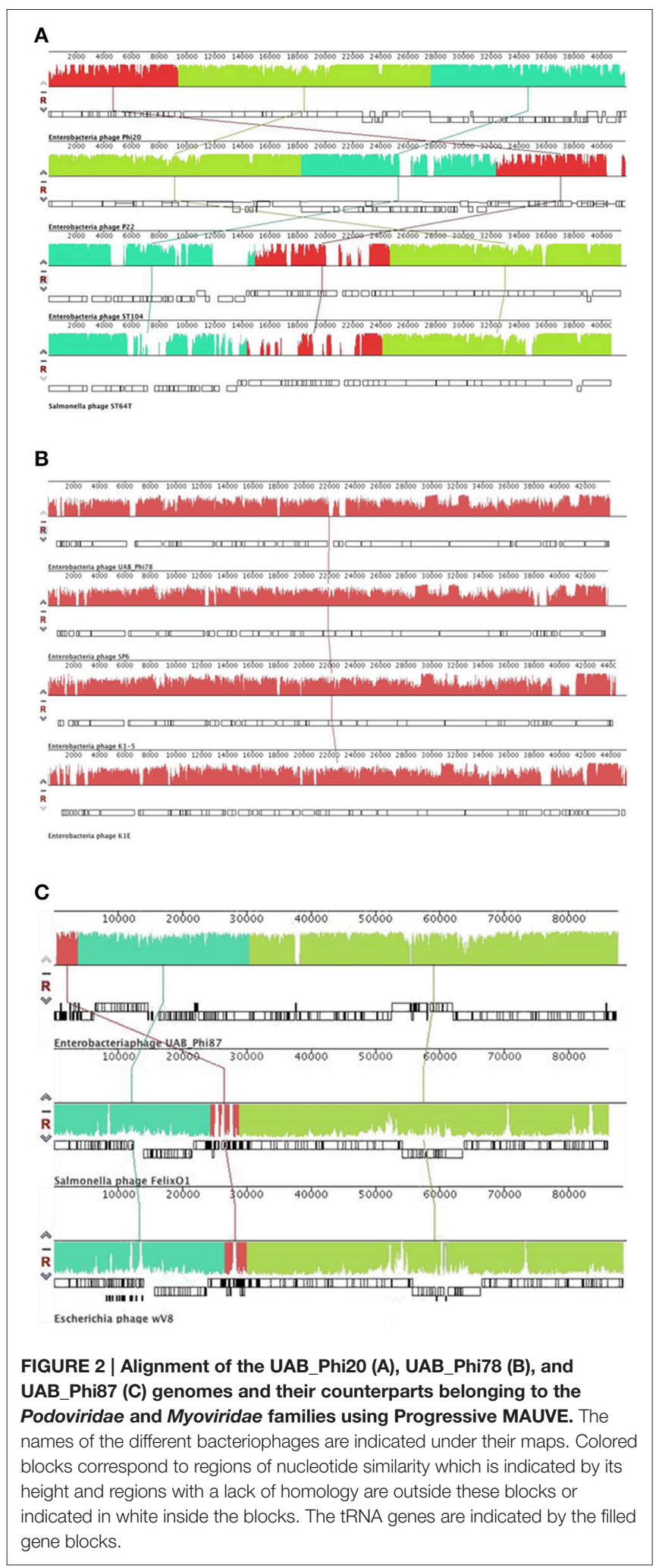

homologous recombination leads to new genetic combinations that give rise to new lambdoid bacteriophages (Thomson et al., 2004).

\section{Genome Analysis of UAB_Phi78}

The UAB_Phi78 genome is a linear dsDNA molecule of 44,110 bp including DTR of $179 \mathrm{bp}$ and with a G+C content of $47.41 \%$, slightly lower than that of Salmonella (52.2\%). Genome analysis predicted 58 putative ORFs (Table 2, Figure 3). The genome annotation of the SP6 bacteriophage (Genbank accession number NC_004831) was used to assign similarities to UAB_Phi78 ORFs because the genome of UAB_Phi78 showed the highest similarity (86\%) with the genome of this phage after analysis with ClustalW2 program.

A BPROM search identified 25 promoters (Table S1). Each had a -10 and -35 consensus sequences, ggTAtaaT and TTGAca, respectively (the conserved bases are indicated in capital letters). Four potential Rho-factor independent terminators were also identified in the UAB_Phi78 genome with FindTerm program (Figure 3). The first was located after gene encoding the RNA polymerase $(g p 8)$; the second and fourth immediately after genes encoding a protein of unknown function, and the third downstream of the gene $(g p 32)$ encoding the major capsid protein. Additionally, a fifth terminator was identified with the Transterm program. This was located after the genes encoding the tail spike protein. For 57 of the 58 predicted genes ATG was the translation initiation codon; in the remaining gene, orf 39 , the start codon was TTG. TAA was the most prevalent (67.2\%) stop codon, followed by TGA and TAG (19 and $13.8 \%$, respectively).

Among the 58 ORFs, 20 could be assigned functions and showed significant similarity with reported proteins of the SP6 bacteriophage (Dobbins et al., 2004). Hypothetical proteins were encoded by 26 ORFs whereas 12 did not show similarity with any gene product of the databases. According to a homology-searchbased annotation the ORFs of UAB_Phi78 were categorized into three functions. Within the metabolic functions, the protein encoded by orf 20 showed significant identity (95\%) with the DNA polymerase encoded by gene SP6 gp14, suggested to be the origin of bidirectional replication in SP6 (Dobbins et al., 2004). Likewise, proteins associated with the DNA metabolism of the phage genome were also identified: RNA polymerase (Gp8), DNA primase (Gp10), exonuclease (Gp21), endonuclease (Gp22), and DNA ligase (Gp25). All of them showed an identity of 95\% with their counterparts in the SP6 genome (Dobbins et al., 2004). It is remarkable that this phage encodes a RNA polymerase that may control the expression of its own DNA polymerase, similar to that described for the phage T7 (Kropinski et al., 2007). This could promote an efficient transcription of UAB_Phi78 genes and justify that the timing of the latent period was significantly lower than that of the other two phages studied in this work (Bardina, 2011; Spricigo, 2011). Accordingly, by PCR amplification, the UAB_Phi78 DNA was detected 10 min after infection of bacterial cells, whereas the UAB_Phi20 and UAB_Phi87 DNA were seen 20 min after infection (data not shown).

Finally, it is noteworthy that protein encoded by orf6 of the UAB_Phi78 bacteriophage has 75\% identity with SP6 Gp5 protein which encodes a putative anti-restriction protein. It has been suggested that it is the responsible for phage multiplication in Salmonella cells with or without its natural type I restriction systems (Scholl et al., 2004). Obviously, this can confer an advantage over other bacteriophages. 
TABLE 2 | Features of bacteriophage UAB_Phi78 genome, ORFs, gene products, and functional assignments.

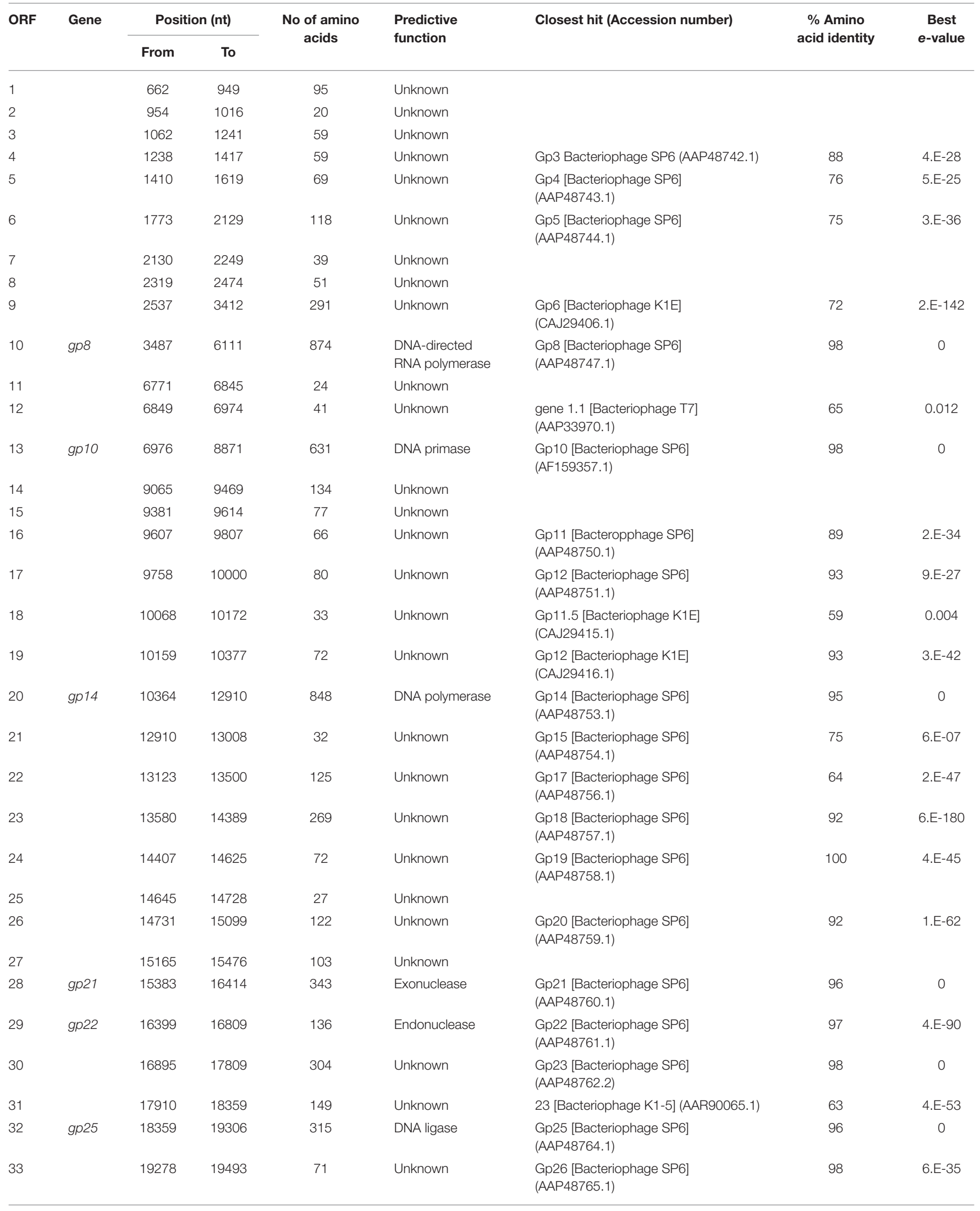


TABLE 2 | Continued

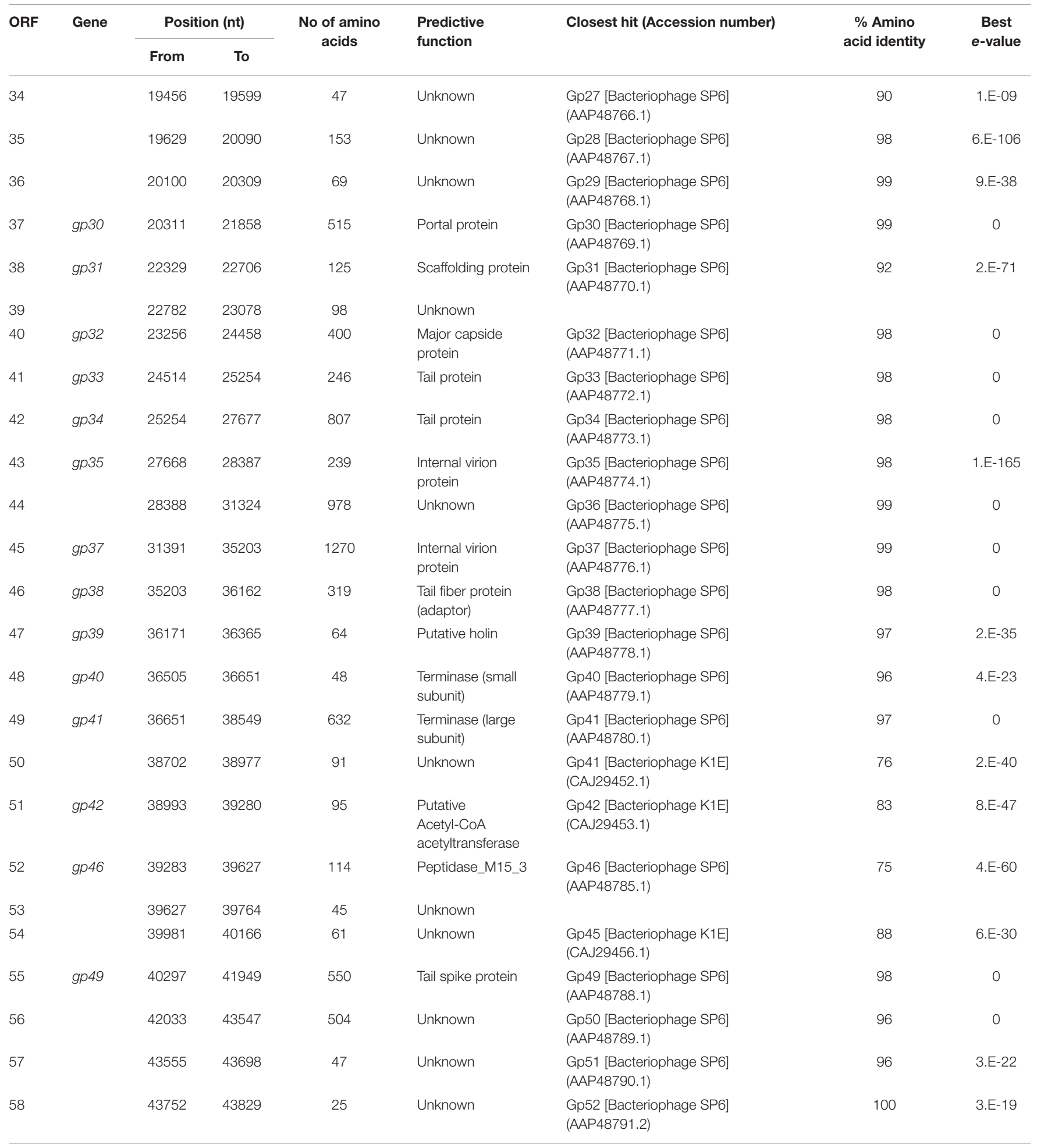

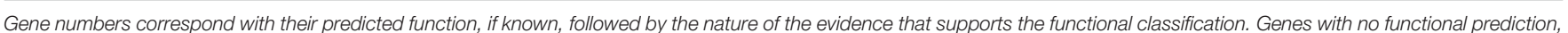
but with significant sequence similarity to genes in the NCBI database as determined by BLASTP are also listed.

With respect to lysis, the orf 47 encoded a protein with a $96 \%$ identity with a putative holin codified in the SP6 gp39 gene. Similar to the results in SP6, K1E, and K1-5 bacteriophages, no endolysin homologous to that encoding T7gp18.5 and involved in lysis was identified (Dobbins et al., 2004; Scholl et al., 2004). This gene has only been identified in the genome of bacteriophage K1F 


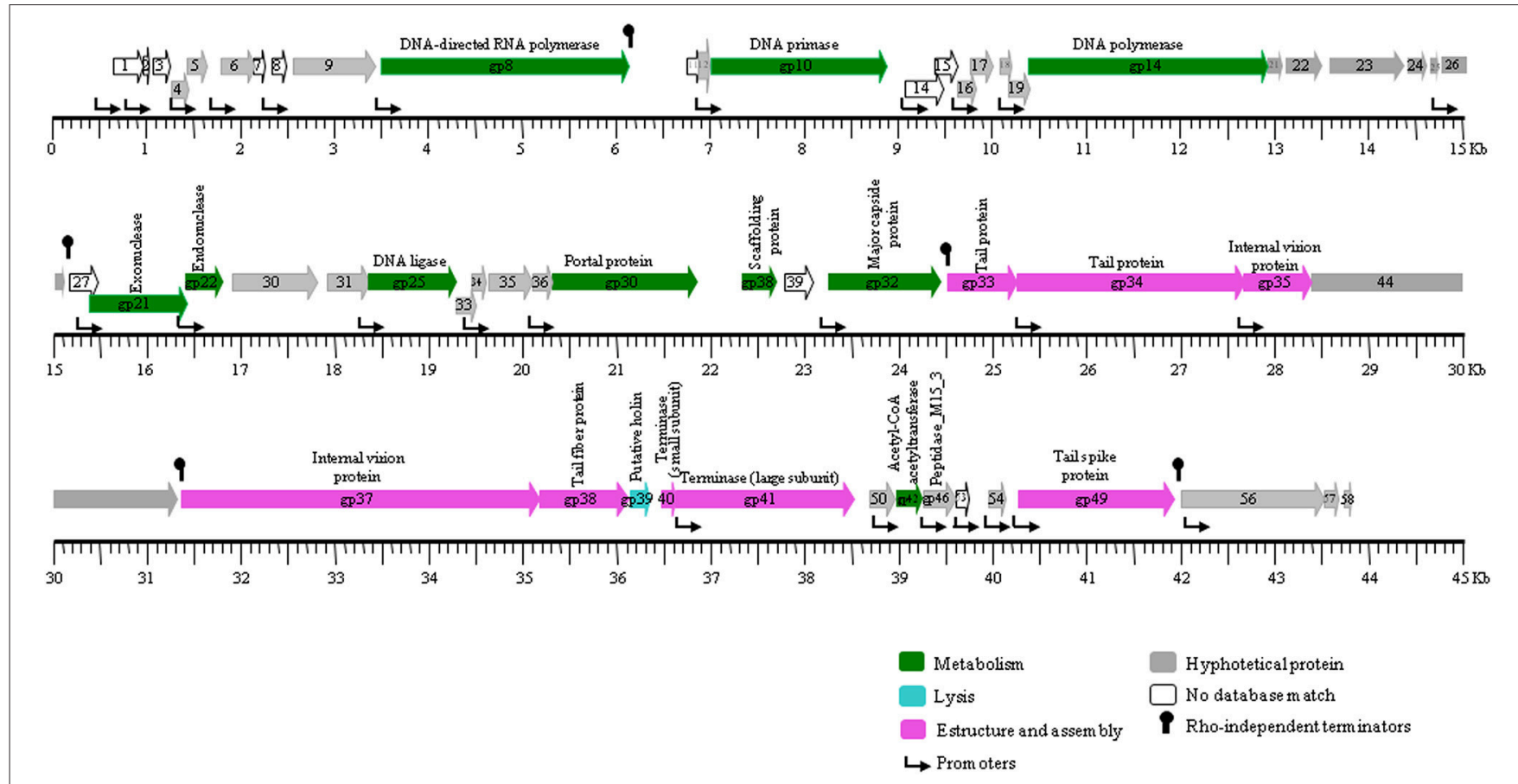

FIGURE 3 | Genomic structure of UAB_Phi78 including the Rho-indepedent terminators. Arrows represent genes, and the different colors identify the functional category into which the homologous genes were classified. Gene functions are indicated where they are known. The color code for gene function is provided at the bottom of the figure. ORFs are numbered consecutively from left to right as described in Table 2, and are indicated by arrows pointing to the direction of transcription.

(Scholl and Merril, 2005) and its expression is necessary only for cell lysis in the presence of high concentrations of divalent cations (Dobbins et al., 2004). It is worth mentioning that protein encoded by orf 44 had a 99\% identity with SP6 Gp36 protein, whose C-terminal sequence showed a slight similarity with that of cell wall lysozymes and its lysozyme activity differed from that of the typical endolysins of similar bacteriophages (Dobbins et al., 2004; Scholl et al., 2004). Moreover, ORF52 had a 75\% identity with SP6 Gp46 protein, recently identified as a peptidase_M15_3 (Oliveira et al., 2013). This protein, also identified in both $\mathrm{K} 1 \mathrm{E}$ and K1-5 phages, is suggested to be an endolysin although without biochemical evidence.

Proteins involved in structure and assembly were encoded in more than half of the UAB_Phi78 genome, from approximately orf37 to orf55 (Table 2; Figure 3). Terminases (Gp40 and Gp41), head portal (Gp30), internal virion (Gp35 and Gp37), tail (Gp33 and Gp34), tail fiber (Gp38), and tail spike (Gp49) proteins were detected in this region, showing a $\geq 91 \%$ similarity with the corresponding proteins of the SP6 bacteriophage. However, three proteins encoded in this region (ORF50, ORF51, and ORF54) showed the highest identity $(>75 \%)$ with hypothetical proteins of the K1E bacteriophage (Scholl et al., 2004) but, no homology was found for protein encoded by orf53 in any database.

UAB_Phi78 has the protein Gp49 and the hypothetical protein encoded by orf56, with a high identity to the counterparts proteins of SP6 (Gp 49 and Gp50 proteins; Table 2) which have been predicted as receptor-binding proteins able to interact with two distinct receptors in the polysaccharide. SP6 Gp49 protein must interact with the Salmonella $\mathrm{O}$-antigen because is closely related to the P22 tail spike protein (Gp9) with endorhamnosidase activity that cleaves the $\alpha 1,3-\mathrm{O}$-glycosidic bond between the repeating tetrasaccharide units of this antigen (Iwashita and Kanegasaki, 1976; Scholl et al., 2004). The second receptor, distinct from $\mathrm{O}$-antigen and recognized by Gp50, was predicted for SP6 bacteriophage because this phage infected a galE mutant of S. Typhimurium LT2 (Scholl et al., 2004; Nguyen et al., 2012). Similarly, we hypothesized that bacteriophage UAB_Phi78 would recognize two receptors. In this sense, the bacteriophage UAB_Phi78 infected galE mutant of $S$. Typhimurium LT2 but not deep rough $(r f a)$ mutants (data not shown). It must be noted that the two other bacteriophages studied here did not infect those mutants (data not shown).

After analysis using CoreGenes (Turner et al., 2013), UAB_Phi78 and SP6 bacteriophages have $~ 83 \%$ of proteins in common. The Rho-independent terminators were in the same position in both genomes, although their sequences showed $<56 \%$ similarity (Dobbins et al., 2004). The main differences between the two bacteriophages occur at the beginning of the sequence of the UAB_Phi78 genome and in the region between DNA primase and DNA polymerase, where there are many genes encoding proteins without defined functions according to the NCBI databases, including a hypothetical protein with unknown function that is also present in bacteriophage $\mathrm{K} 1 \mathrm{E}$ (Gp12). Moreover, UAB_Phi78 shared 80 and 69\%, respectively 
TABLE 3 | Features of bacteriophage UAB_Phi87 genome, ORFs, gene products, and functional assignments.

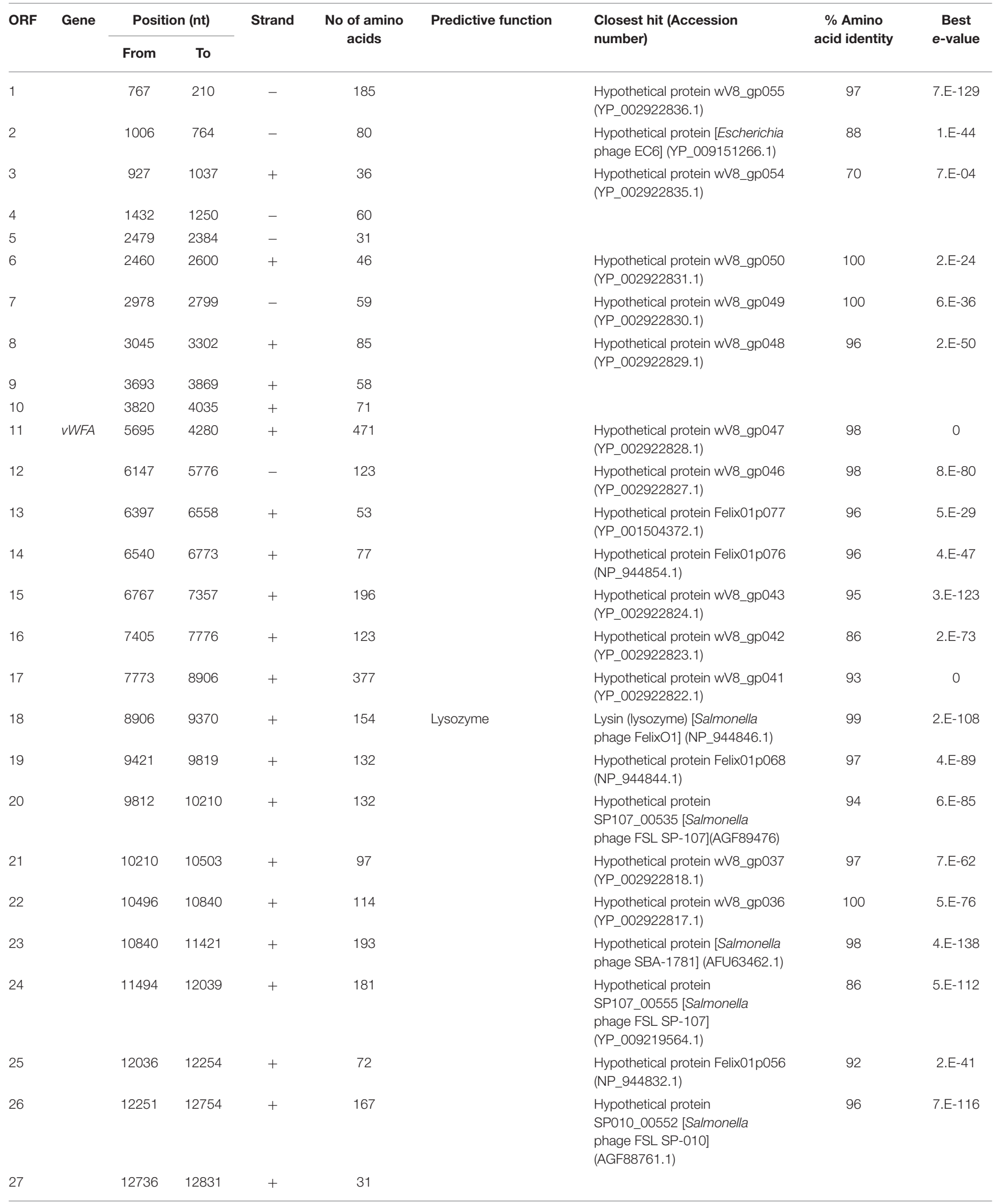


TABLE 3 | Continued

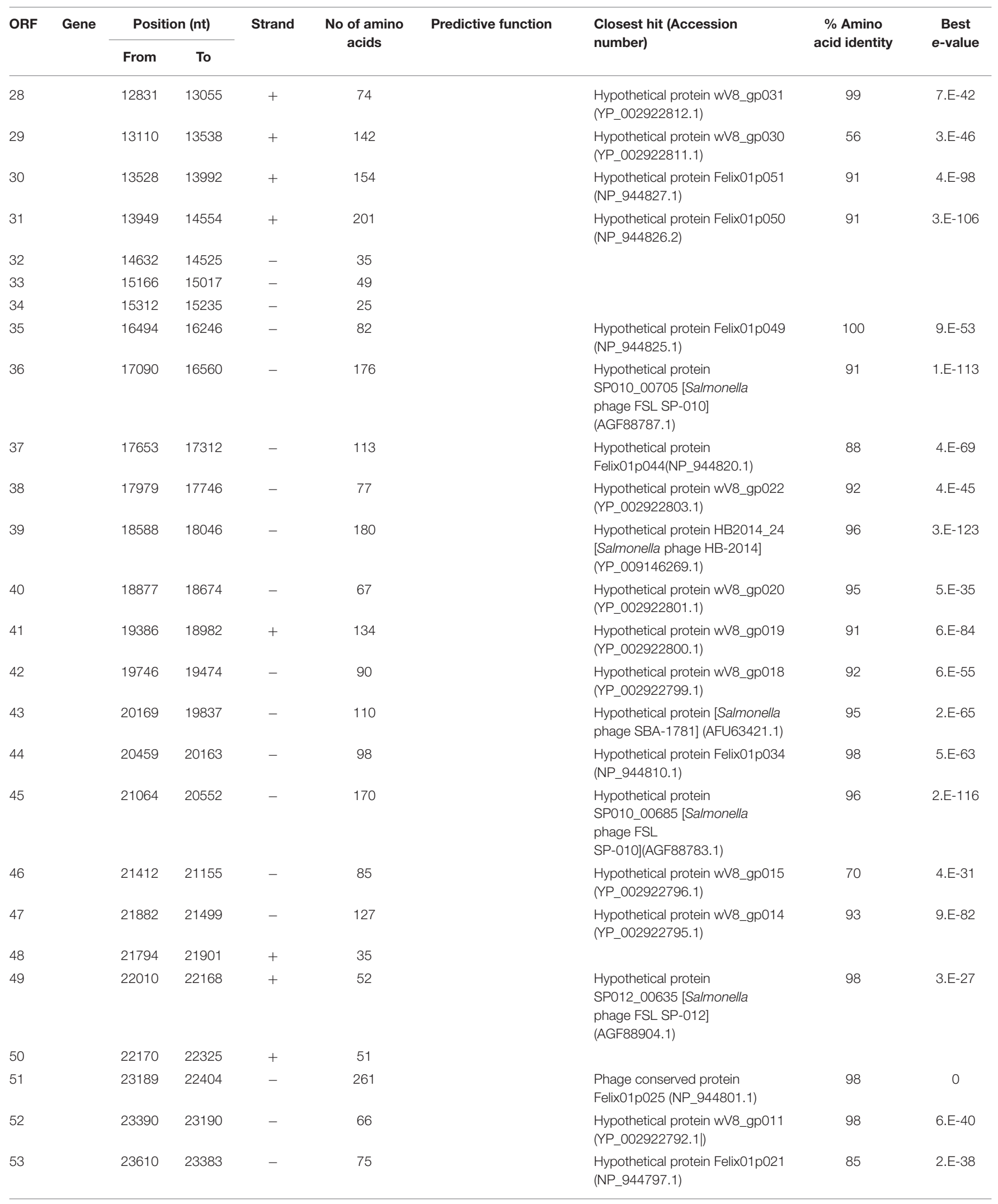


TABLE 3 | Continued

\begin{tabular}{|c|c|c|c|c|c|c|c|c|c|}
\hline ORF & Gene & \multicolumn{2}{|c|}{ Position (nt) } & Strand & $\begin{array}{l}\text { No of amino } \\
\text { acids }\end{array}$ & Predictive function & $\begin{array}{l}\text { Closest hit (Accession } \\
\text { number) }\end{array}$ & $\begin{array}{l}\% \text { Amino } \\
\text { acid identity }\end{array}$ & $\begin{array}{c}\text { Best } \\
\text { e-value }\end{array}$ \\
\hline 55 & & 24215 & 23901 & - & 104 & & $\begin{array}{l}\text { Hypothetical protein Felix01p017 } \\
\text { (NP_944793.2) }\end{array}$ & 100 & 6.E-69 \\
\hline 57 & & 24747 & 24478 & - & 89 & & $\begin{array}{l}\text { Hypothetical protein Felix01p015 } \\
\text { (NP_944791.1) }\end{array}$ & 99 & 2.E-56 \\
\hline 58 & & 24988 & 24641 & - & 115 & & $\begin{array}{l}\text { Phage conserved protein } \\
\text { Felix01p014 (NP_944790.1) }\end{array}$ & 100 & 3.E-78 \\
\hline 59 & & 25505 & 25041 & - & 154 & & $\begin{array}{l}\text { Hypothetical protein wV8_gp005 } \\
\text { (YP_002922786.1) }\end{array}$ & 100 & 2.E-104 \\
\hline 61 & & 26737 & 26189 & - & 182 & & $\begin{array}{l}\text { Hypothetical protein wV8_gp003 } \\
\text { (YP_002922784.1) }\end{array}$ & 99 & 2.E-128 \\
\hline 62 & $r l l B$ & 27947 & 26838 & - & 369 & & $\begin{array}{l}\text { rllB protein [Escherichia phage } \\
\text { wV8] (YP_002922783.1) }\end{array}$ & 98 & 0 \\
\hline 63 & $r \| A$ & 30393 & 28027 & - & 788 & & $\begin{array}{l}\text { rllA protein [Salmonella phage } \\
\text { FSL SP-010] (AGF88671.1) }\end{array}$ & 98 & 0 \\
\hline 64 & & 30598 & 30422 & - & 58 & & $\begin{array}{l}\text { Hypothetical membrane protein } \\
\text { Felix01p243 (NP_945023.1) }\end{array}$ & 95 & 8.E-32 \\
\hline 65 & & 30915 & 30580 & - & 111 & & $\begin{array}{l}\text { Hypothetical protein } \\
\text { SP010_00075 [Salmonella } \\
\text { phage FSL SP-010] } \\
\text { (AGF88673.1) }\end{array}$ & 97 & 4.E-73 \\
\hline 68 & & 33971 & 33693 & - & 92 & & $\begin{array}{l}\text { Hypothetical protein Felix01p233 } \\
\text { (NP_945013.1) }\end{array}$ & 96 & 1.E-59 \\
\hline 69 & & 34479 & 33964 & - & 171 & & $\begin{array}{l}\text { Hypothetical protein } \\
\text { SP10700240 [Salmonella phage } \\
\text { FSL SP-107] (AGF89418.1) }\end{array}$ & 96 & 8.E-121 \\
\hline 70 & & 34851 & 34531 & - & 106 & & $\begin{array}{l}\text { Hypothetical protein Felix01p227 } \\
\text { (NP_945007.1) }\end{array}$ & 97 & 8.E-67 \\
\hline 71 & & 35111 & 34854 & - & 86 & & $\begin{array}{l}\text { Hypothetical protein wV8_gp132 } \\
\text { (YP_002922914.1) }\end{array}$ & 99 & 6.E-52 \\
\hline 72 & $n r d G$ & 35721 & 35236 & - & 161 & $\begin{array}{l}\text { Anaerobic NTP } \\
\text { reductase }\end{array}$ & $\begin{array}{l}\text { NrdG, small subunit [Escherichia } \\
\text { phage wV8] (YP_002922912.1) }\end{array}$ & 95 & 2.E-112 \\
\hline 73 & & 36176 & 35781 & - & 131 & & $\begin{array}{l}\text { Hypothetical protein } \\
\text { SP10700210 [Salmonella phage } \\
\text { FSL SP-107] (AGF89412.1) }\end{array}$ & 95 & 5.E-89 \\
\hline 74 & & 36373 & 36173 & - & 66 & & $\begin{array}{l}\text { Hypothetical membrane protein } \\
\text { Felix01p221 (NP_945001.1) }\end{array}$ & 97 & 2.E-37 \\
\hline 75 & & 36474 & 36349 & - & 41 & & $\begin{array}{l}\text { Hypothetical membrane protein } \\
\text { Felix01p220 (NP_945000.2) }\end{array}$ & 90 & 3.E-17 \\
\hline
\end{tabular}


TABLE 3 | Continued

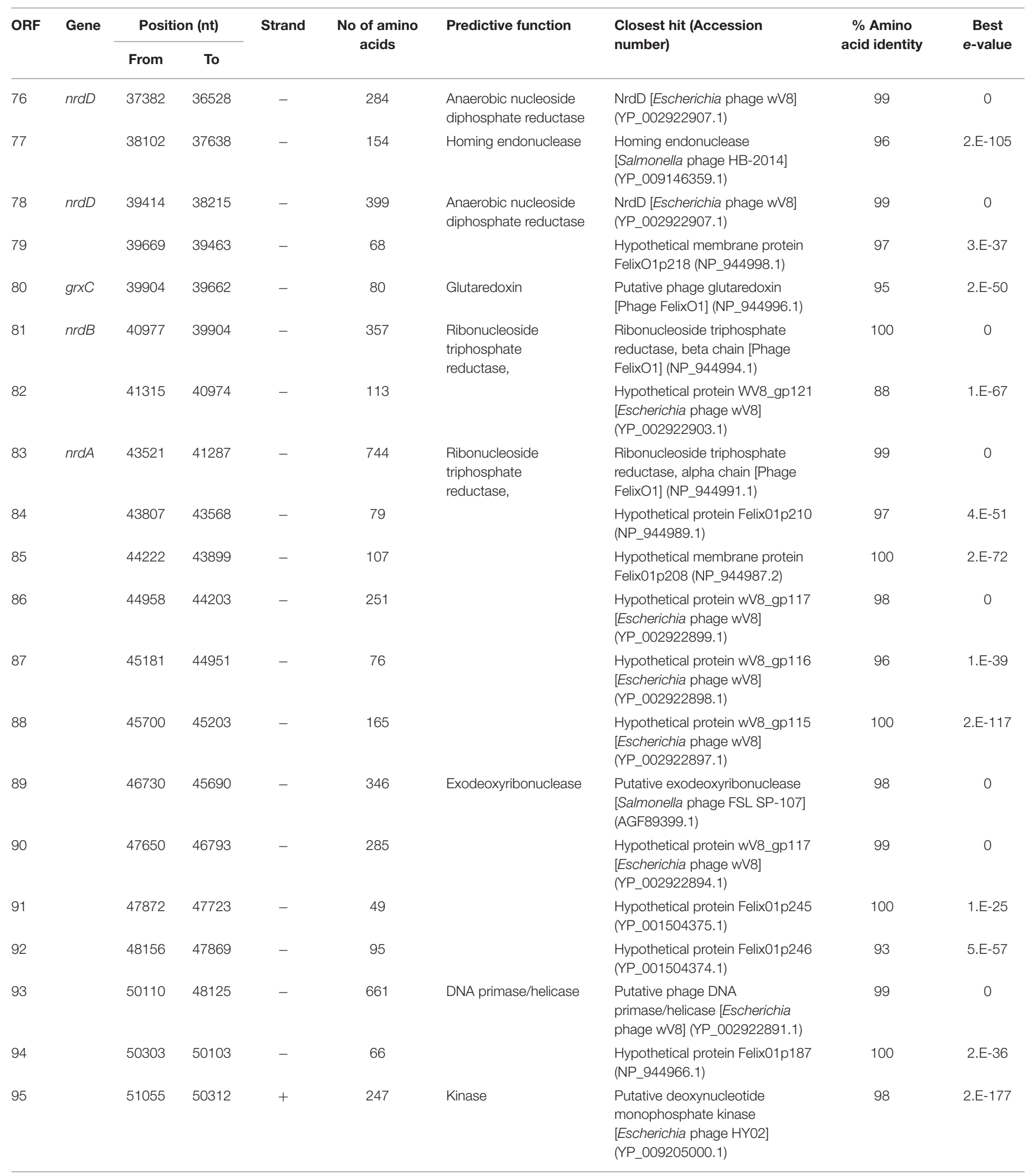


TABLE 3 | Continued

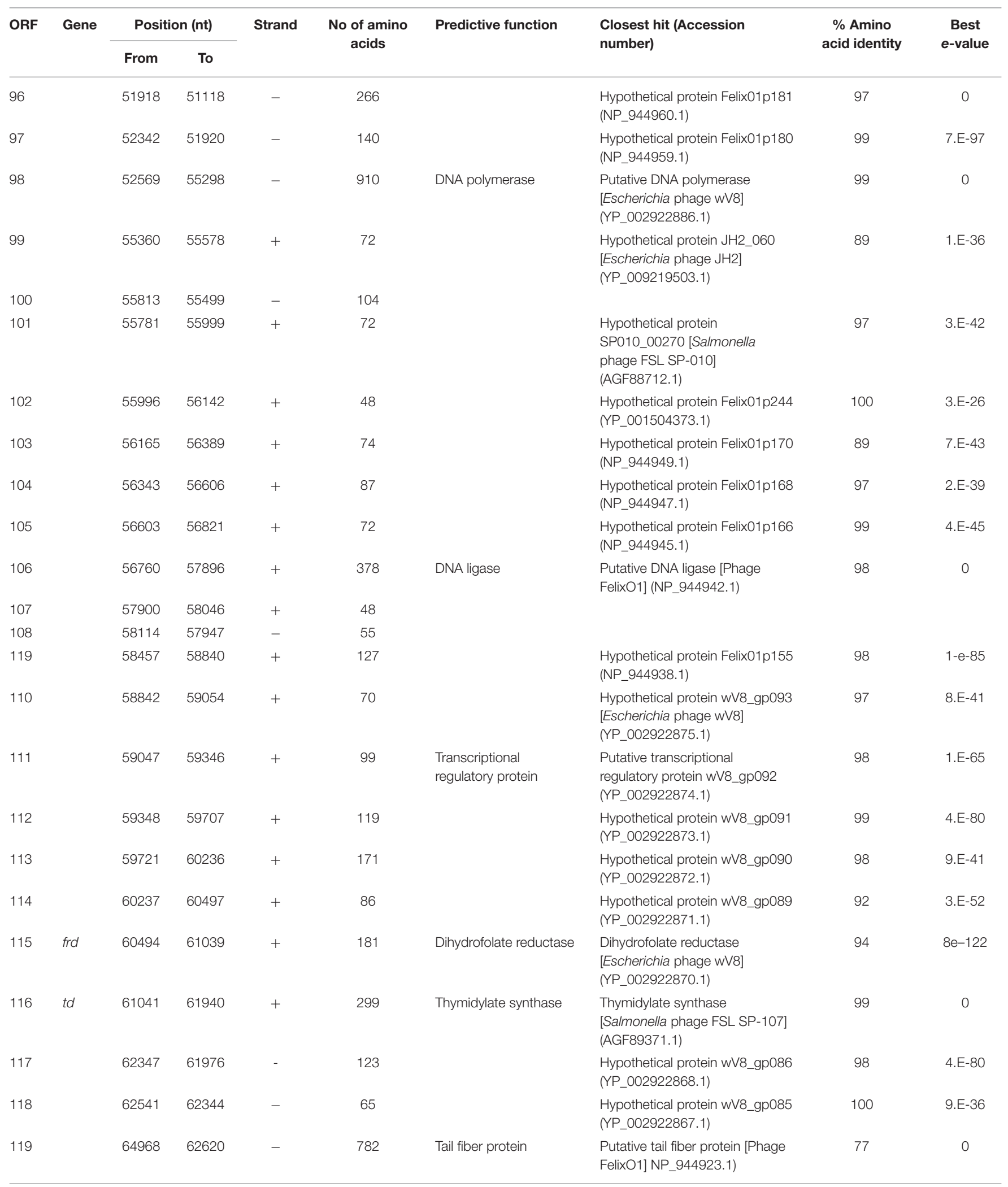


TABLE 3 | Continued

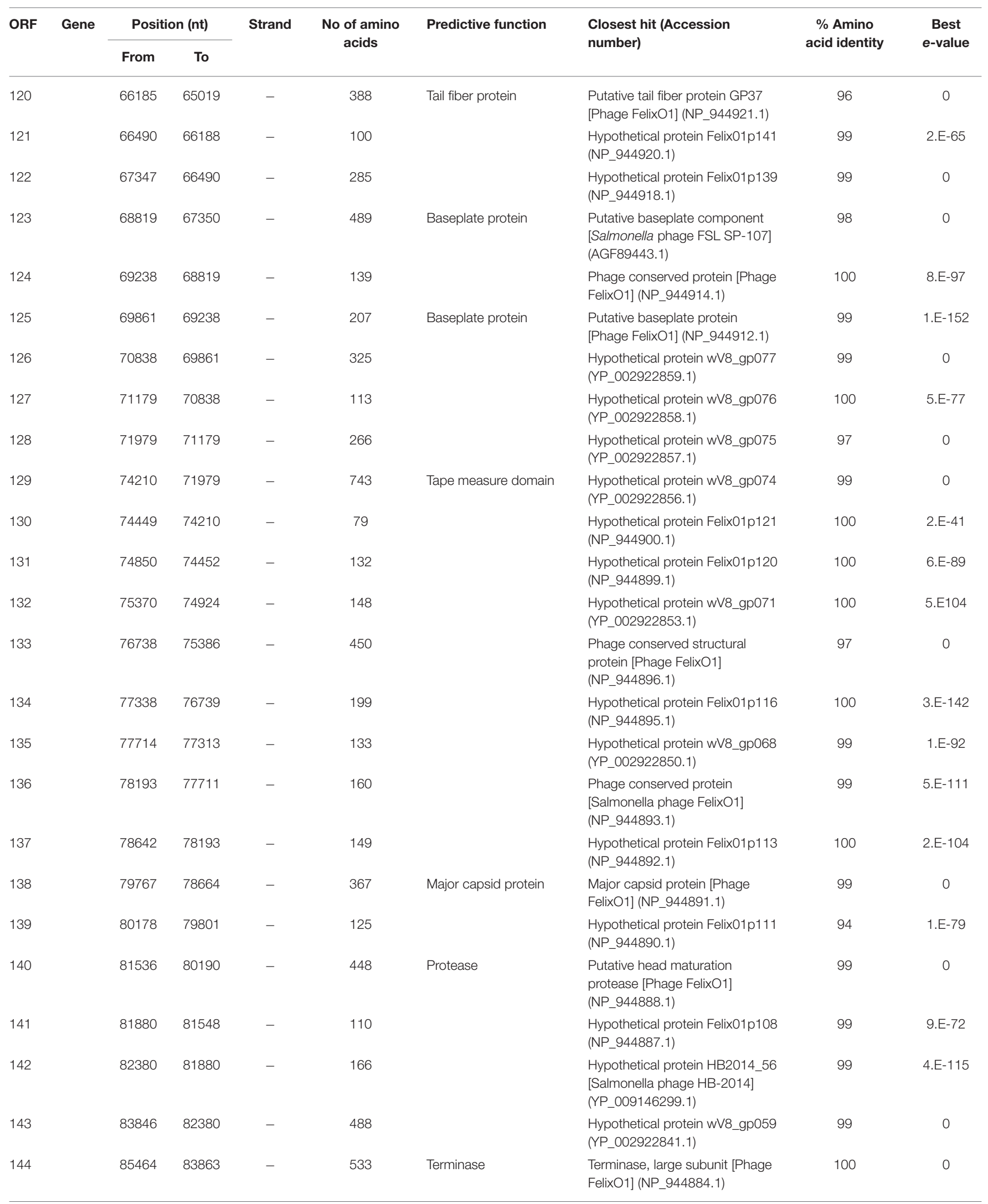


TABLE 3 | Continued

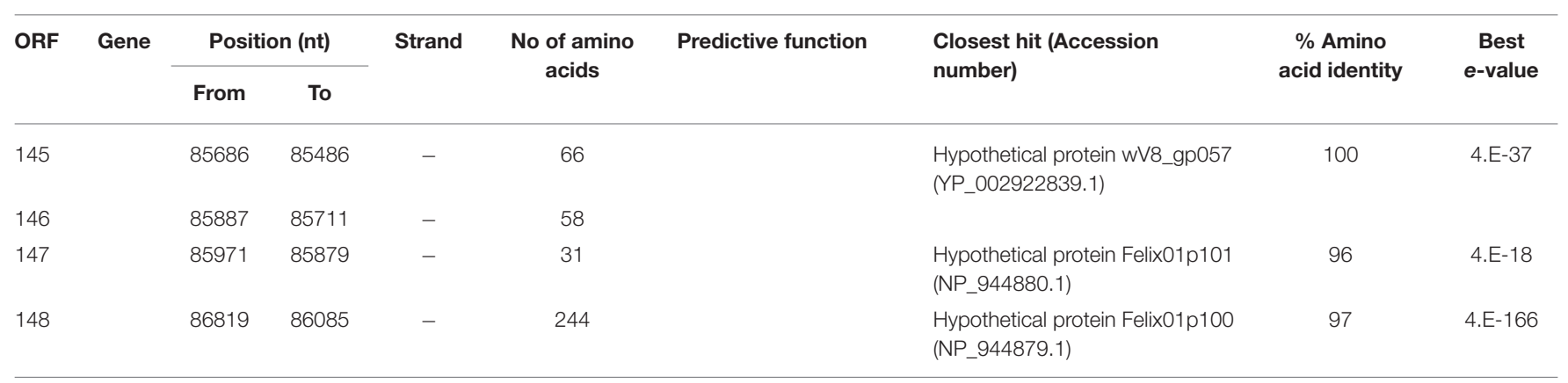

Gene numbers correspond with their predicted function, if known, followed by the nature of the evidence that supports the functional classification.

Genes with no functional prediction, but with significant sequence similarity to genes in the NCBI database as determined by BLASTP are also listed.

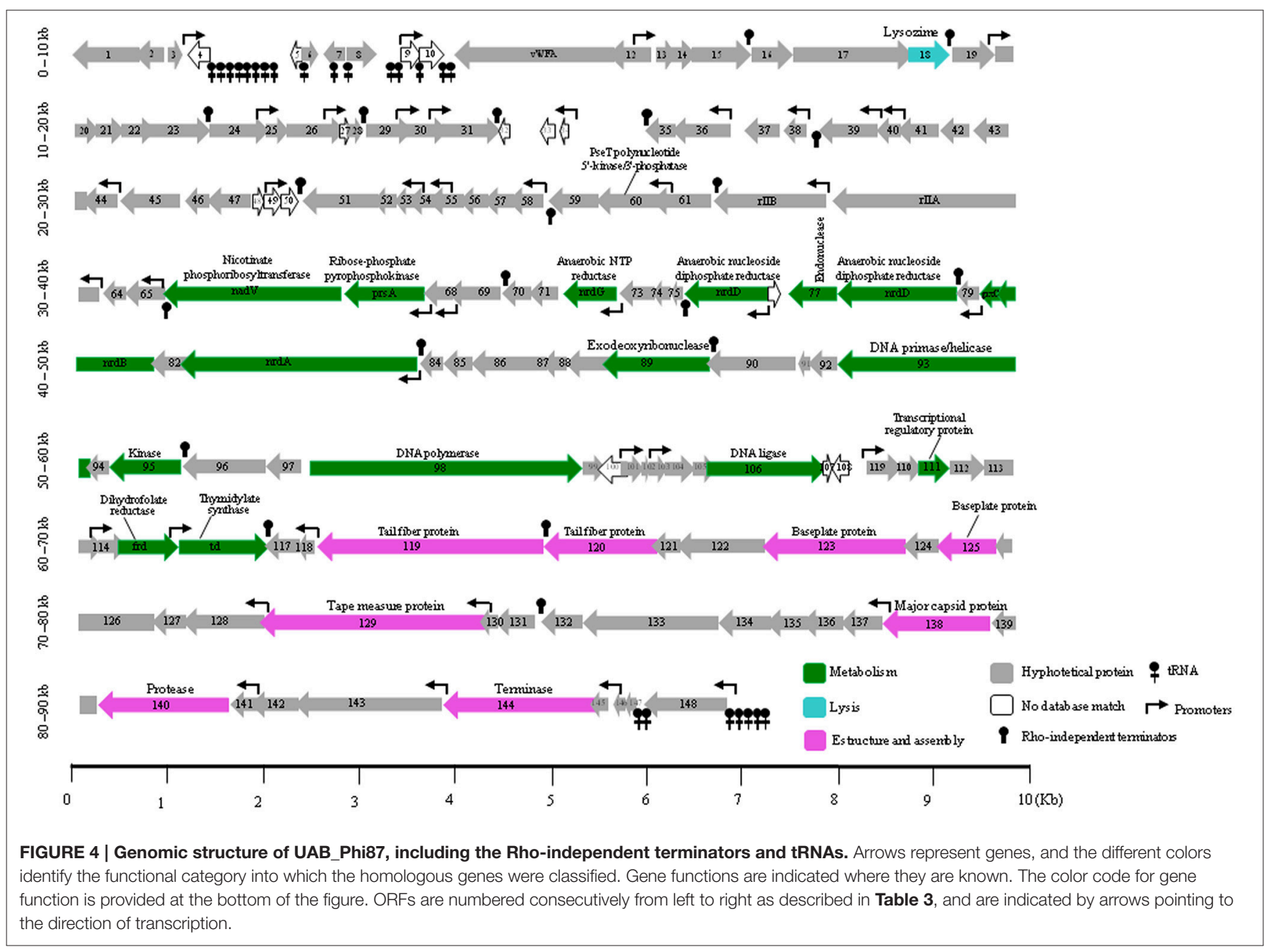

of its proteome with those of E. coli bacteriophages as K1-5 and K1E.

Therefore, UAB_Phi78 belongs to Sp6likevirus genus of the Podoviridae family (Lavigne et al., 2008), which includes $>35 \%$ of Salmonella bacteriophages (Abedon et al., 2011). An alignment of the annotated genomes of these four bacteriophages using Mauve reveals that their shared genes are largely collinear, with few noticeable differences at $\sim 1-2,6.7,22$, and $39 \mathrm{~Kb}$ on the UAB_Phi78 genome with respect to the others (Figure 2).

\section{Genome Analysis of UAB_Phi87}

The complete sequenced genome of UAB_Phi87 consisted of $87,669 \mathrm{bp}$, with DTR of $608 \mathrm{bp}$ and with a G+C percentage of $38.9 \%$, clearly lower than that of Salmonella $(52.2 \%)$. The 
UAB_Phi87 genome contained 210 putative ORFs, of which 148 were finally selected (Table 3); the remaining 62 were in regions that overlap with these 148 ORFs. Putative functions could be assigned only to 29 (19\%) of the 148 ORFs based on protein sequence similarities. The other 119 ORFs consisted of hypothetical proteins without assigned function. Of these, 104 showed high similarities with hypothetical proteins of bacteriophages Felix $\mathrm{O} 1$ of Salmonella, wV8 of E. coli, and in a lesser extent of Salmonella FSL SP107, FSL SP010, and FSL SP012. Fifteen of these 119 ORFs were apparently unique to UAB_Phi87 and they lacked similarity with sequences deposited in the databases. Potential Shine-Dalgarno sequences were highly conserved (AGGAGGA) and, the mean distance between this consensus sequence and the majority of RBS was $14 \mathrm{bp}$. Up to 42 hypothetical promoters, with highly conserved consensus sequences at -10 (TATAAT) and - 35 (TTGACA), were detected (Table S1). The high degree of conservation of these sequences and their similarity with those of prokaryote promoters could be a general advantage for phage, as following infection they would be recognized by host bacteria. Twenty Rho-independent terminators were identified by FindTerm (Figure 4). Almost all of the ORFs (146 out of 148) started with an ATG codon; the exceptions were orf118 and orf144, in which TTG was the start signal. As for the stop codons, most ORFs contained a TAA codon $(67.1 \%)$. TGA was present in $25.5 \%$ of the remaining ORFs and TAG in $7.4 \%$. The genome of UAB_Phi87 contains 23 tRNA genes and three of them $(13,18$, and 20) may code pseudo-tRNA (Table S2). From the 20 functional tRNAs, 9 were found to be present at a frequency 1.5 times higher in the phage than in Salmonella. The high number of tRNA has been also documented in other Felixounalikeviruses (Whichard et al., 2010). Their presence seems to compensate for differences in codon usage between the phage and the host and to enable a positive impact on translation of phage-derived mRNA and its infectivity (Bailly-Bechet et al., 2007). Moreover, and similar to bacteriophage Felix O1, the presence of a Met tRNA suggested a positive role for this tRNA in translational initiation in phageinfected cells (Whichard et al., 2010).

The UAB_Phi87 ORFs encoding proteins with known functions were classified into three functional groups (Figure 4). The first one included proteins involved in nucleotide metabolism, which would allow phage replication and transcriptional control of the host machinery. Thus, DNA polymerase (orf98), DNA primase/helicase (orf93), DNA ligase (orf106), and other proteins encoded by genes frd, nadV, nrdA, $n r d B, n r d D, n r d G, \operatorname{prs} A$, and $t d$ involved in the nucleotide metabolism were identified and presented an identity $\geq 94 \%$ with the counterpart proteins of the bacteriophages Felix O1 and FSL SP107 of Salmonella, and wV8 of E. coli. As it has been reported for some bacteriophages of Felixounalikeviruses genus (Moreno Switt et al., 2013), one split gene ( $n r d D)$ encoding the anaerobic ribonucleotide reductase was identified in UAB_Phi87. A gene (orf77) encoding a putative homing endonuclease interrupted the $n r d D$ gene. In addition, this genetic structure also was in HB2014 and JH2 phages of the Myoviridae family as we determined by bioinformatic analysis. The UAB_Phi87 homing endonuclease had an identity of $95-96 \%$ with the counterpart protein of all these bacteriophages and a $53 \%$ to that of the JSE bacteriophage, which belongs to the T4 group of bacteriophages infecting $E$. coli. Bacteriophages of this group, as T4 and JSE, and those of the Felixounalikeviruses genus typically possess several homing endonucleases (Whichard et al., 2010). Thus, T4 and Felix O1 bacteriophages encodes for 15 and 6 homing endonucleases, respectively. In contrast, in the UAB_Phi87 genome only a gene coding a homing endonuclease was identified.

The unique gene (orf18) with a clear function in lysis encoded a lysin with a 99\% identity with the counterpart of Felix O1 bacteriophage. As in this phage, UAB_Phi87 lacks a holin gene adjacent to the lysin gene. Thus, as suggested for Felix O1 (Whichard et al., 2010), one as yet unidentified protein with unknown function located elsewhere in the UAB_Phi87 genome may assume that function. The UAB_Phi87 genome also contains $r I I A$ and $r I I B$ genes, first described in bacteriophage T4 (Miller et al., 2003), which encoded membrane-associated proteins of poorly understood function in this phage. It has been suggested that both could be indirectly involved in lysis inhibition, perhaps by perturbing membrane functions (Burch et al., 2011) when bacterial cells are reinfected by other T4 bacteriophages. It must be noted that UAB_Phi87 DNA was detected inside infected cells more than $100 \mathrm{~min}$ by PCR

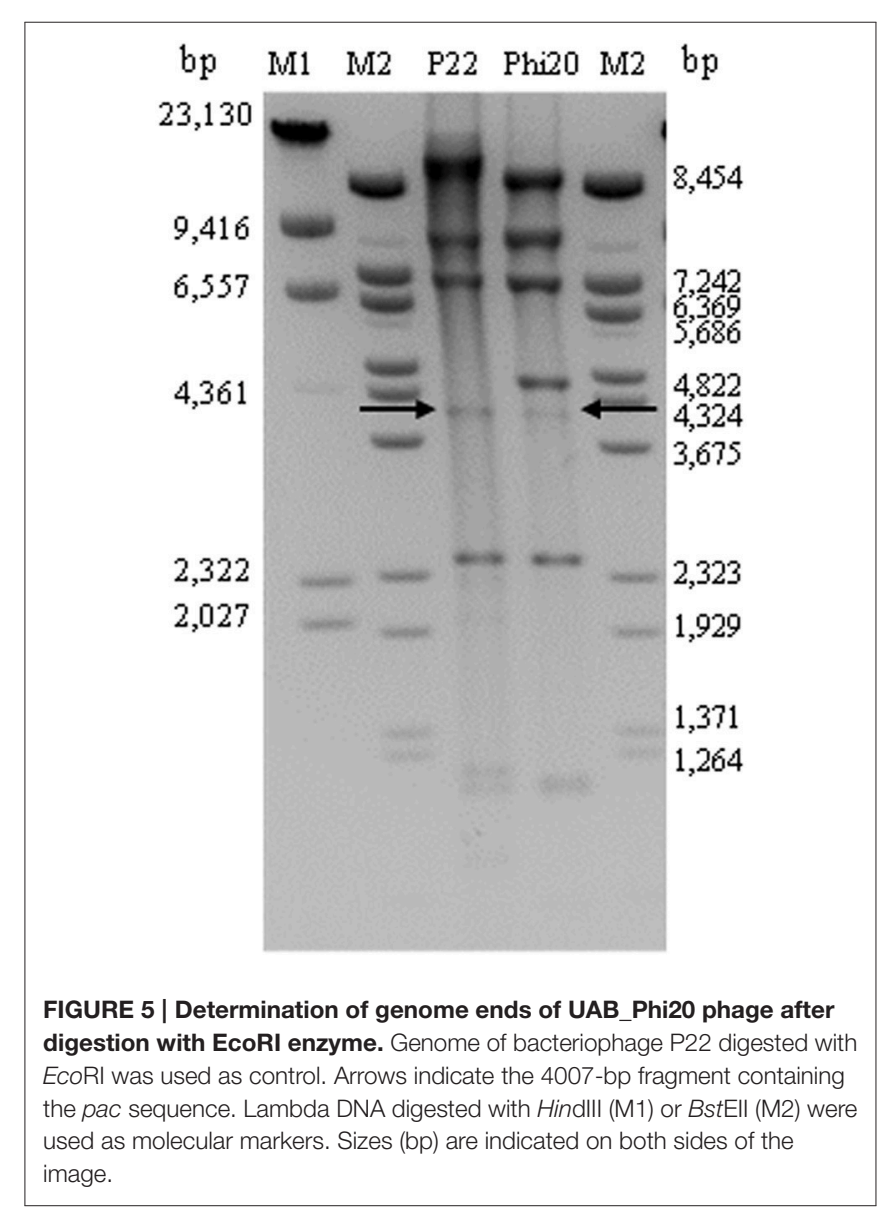



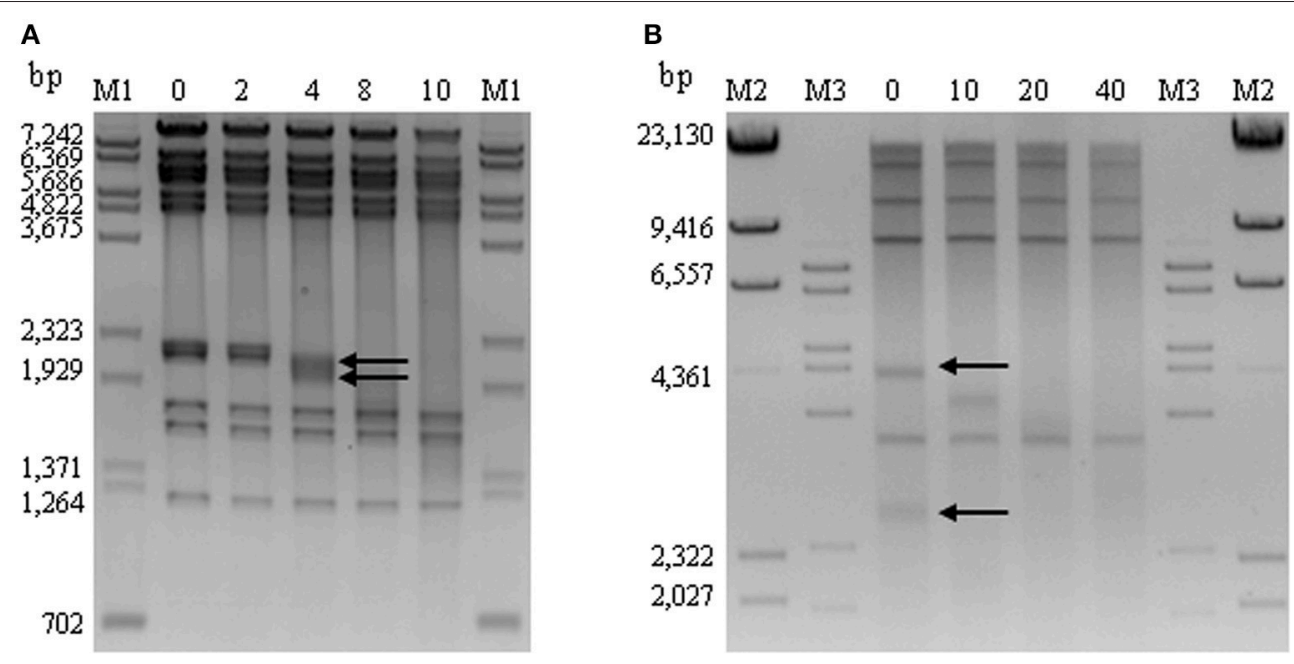

FIGURE 6 | Time-limited digestion with Bal31 exonuclease of UAB_Phi78 and UAB_Phi87 DNA followed by digestion with HindIII and Spel, respectively. Arrows indicate the sequentially degraded DNA bands of 2200 and 2080 bp for UAB_Phi78 (A) and of 4322 and 2819 bp for UAB_Phi87 (B). M: marker lanes containing a mixture of $\lambda$ DNA digested with BstEll and $\varphi$ X174 digested with Hinfl (M1), $\lambda$-DNA-digested HindllI (M2), and $\lambda$-DNA-digested BstEll (M3). Sizes (bp) are indicated on the left side of the images.

amplification (data not shown) which could be related to this phenomenon.

The third functional group contained structure and assembly proteins and included tail fiber (ORF119 and ORF120), baseplate (ORF123 and ORF125), tape measure (ORF129), major capsid (ORF138) proteins, and a putative head maturation protease (ORF140). All of them presented a high identity with their counterparts of FelixO1, FSL SP-107, and wV8 phages. Only, ORF119 showed lower identity (77\%) with respect to the corresponding putative tail fiber of FelixO1 (Table 3). At difference of many phages and similar to Felix O1 phage, only a large terminase (ORF144) was identified in the UAB_Phi87 genome (Whichard et al., 2010) with a $100 \%$ of identity. As it had been reported these large terminases presented similarity with Erwinia amylovora $\Phi$ E21-4 phage, and $\mathrm{wV} 8$ and rV5 phages which infected E. coli (Whichard et al., 2010).

After CoreGenes analysis, the proteome of UAB_Phi87 shared $\leq 90 \%$ with those of FelixO1 and wV8. This allows classifying UAB_Phi87 as belonging to Felixounalikevirus genus of Myoviridae family. A MAUVE comparison of these four genomes agrees with the results of protein-by-protein comparison, and revealed the mosaic structure of the UAB_Phi87 genome and also its high similarity in terms of both genetic content and functional organization with the genomes of the other bacteriophages (Figure 2).

\section{Determination of the Genome Ends of UAB_Phi20, UAB_Phi78, and UAB_Phi87 Bacteriophages}

Six types of ends are well-known in the lineal dsDNA contained in the tailed-bacteriophage virions: (i) single-stranded cohesive ends (cos ends), (ii) circularly permuted DTR, (iii) short, several hundred base pairs exact DTR, (iv) long, several thousand base pairs exact DTR, (v) terminal host sequences, and (vi) covalently bound terminal proteins (Casjens and Gilcrease, 2009). The first five types of ends are produced by the cleavage of DNA concatemers consequence of the phage DNA replication. These cleavages are closely tied with the phage DNA packaging due to terminases encoded by the phage itself.

After sequencing the genomes, we did not obtain a clear evidence of the ends of the chromosomes of UAB_Phi20, UAB_Phi78, and UAB_Phi87 bacteriophages. In order to clarify this and their packaging strategy, firstly, the DNA of the phages was obtained and digested with EcoRV enzyme. Afterwards the restriction product was heat treated prior electrophoresis. Results did not evidence any change of the restriction patterns of DNA treated and untreated with heat (data not shown), showing that the chromosome of these bacteriophages did not present cos ends.

Because of the high similarity of UAB_Phi20 genome with those of bacteriophages of the P22likevirus genus and the identification of a pac site in its genome, we believe that this phage would have circularly permuted DTR. This was confirmed by observing the under-representation of one 4007 bp DNA fragment (Figure 5), which would contain the pac sequence, in EcoRI digested genome. This result is expected for bacteriophages, as P22 phage, which presents this type of ends in their chromosomes (Casjens and Gilcrease, 2009) (Figure 5). Following, we studied if the chromosome ends of UAB_Phi78 and UAB_Phi87 bacteriophages presented DTR in the ends of their chromosomes. Time-limited treatment of their DNA with exonuclease Bal31 followed by digestion with HindIII and SpeI enzymes, respectively, revealed the disappearance of two fragments in their respective restriction 


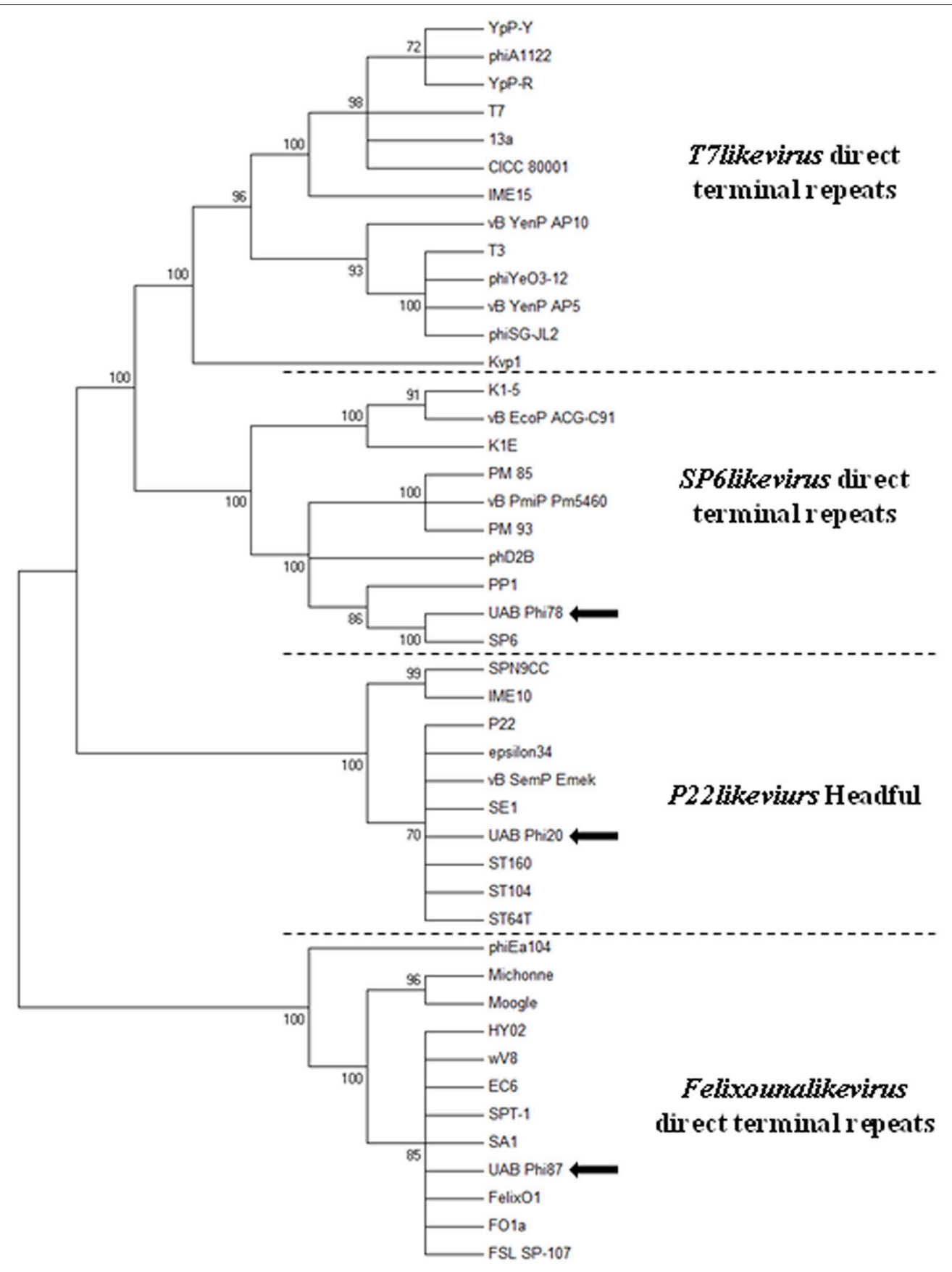

FIGURE 7 | Neighbor-joining phylogenetic tree of large terminase subunit sequences of bacteriophages UAB_Phi20, UAB_Phi78, and UAB_Phi87 (indicated by arrows) and comparison to other phages with known packaging mechanisms. Bootstrap analysis was performed with 1000 repetitions. The node of phylogenetic tree shows the bootstrap confidence values above $70 \%$.

patterns. Thus, in UAB_Phi78, two fragments of 2212 and 2109 bp were simultaneously degraded whereas in UAB_Phi87 the disappearance of two fragments of 4322 and 2819 bp was observed (Figure 6). These data indicated that the degraded fragments contained the chromosomal ends of both UAB_Phi78 and UAB_Phi87 bacteriophages. According to this, specific primers were designed and used for sequencing the recovered and purified restriction fragments as templates. The primers that displayed drop-offs of the sequencing signal were selected and used to confirm the genome end sequences. For this, the respective phage genome was used as template and typical sudden drop-offs of the sequencing signal were observed (Figure S1). The analysis of the sequences obtained allowed us to identify short DTR of 179 and 608 bp for UAB_Phi78 and UAB_Phi87, 
respectively (Figure S1). The size of the UAB_Phi78 DTR was similar to that described in bacteriophage SP6 (Dobbins et al., 2004; Scholl et al., 2004). Likewise, DTR of FelixO1 (Whichard et al., 2010) and FO1a (Marti, 2013) bacteriophages had a similar size to those of UAB_Phi87.

It has been reported that the packaging mechanisms, and in consequence, the type of chromosome ends of bacteriophages can be predicted comparing the amino acid sequences of the known large terminase subunits with similar enzymatic end-generating functions which usually cluster together (Casjens et al., 2005). According to this, when the neighbor-joining tree was elaborated four clusters were seen and the terminases of the UAB_Phi20, UAB_Phi78, and UAB_Phi87 bacteriophages grouped together with those of bacteriophages with similar enzymatic end-generating functions (Figure 7). In this sense, UAB_Phi87 large terminase clustered into the Felixounalikevirus DTR group, and it was highly similar to terminases of Salmonella phages Felix O1 and FO1a, both with DTR in their chromosome ends (Whichard et al., 2010; Marti, 2013). In the same cluster were located terminases of phages wV8 and HY02 which infect E. coli and others from phages infecting E. amylovora or Citrobacter. UAB_Phi78 large terminase clustered together with that of Salmonella phage SP6 and Lelliottia phage phD2B which is a Sp6likevirus genus with a short DTR of $262 \mathrm{pb}$ (Nowicki et al., 2014). As it was expected, the UAB_Phi20 large terminase clustered into the P22likevirus headfull group which included bacteriophages of P22likevirus genus as P22, ST64T or ST160. Thus, and as it has been pointed out (Casjens et al., 2005), the structure of virion DNA ends can be accurately predicted for phages although there is no previous experimental evidences, if their putative terminase amino acid sequence falls convincingly within one of those robust groups.

\section{CONCLUSIONS}

Phage therapy is becoming an alternative or additional strategy to actual treatments of bacterial infections that can also help to diminish the emergence of antibiotic-resistant bacteria with difficult treatment. The use of bacteriophages requires a detailed characterization of these viruses. In this study, the genomes of three virulent Salmonella specific bacteriophages (UAB_Phi20, UAB_Phi78, and UAB_Phi87) were characterized in depth by functional genomic tools and their chromosomal ends were also determined. Detailed genome sequence analyses provided information about the three bacteriophages studied do not encode known virulenceassociated or antibiotic resistance genes. The bacteriophages UAB_Phi78 and UAB_Phi87 contain terminal direct repeats in their chromosome which were identified. The UAB_Phi20 bacteriophage has a chromosome with circularly permuted DTR and it did not give rise to stable lysogens probably due to its inability to synthesize the lytic cycle repressor. This is consistent with both the complete clearance of infected-Salmonella cultures and the production of typical clear plaques. Genomic data and the comparison of terminases allow us the assignment of UAB_Phi20, UAB_Phi78, and UAB_Phi87 to the P22likeviruses genus, SP6likeviruses genus, and Felixounalikeviruses genus, respectively. This confirms the assignation reported for these bacteriophages obtained by different methods (Grose and Casjens, 2014). All the data obtained contribute to a better understanding of the biology of these phages which is necessary for the development and the use of an efficient cocktail with commercial applications in bacteriophage therapy as it has been showed (Bardina et al., 2012; Spricigo et al., 2013; Colom et al., 2015). The success of this cocktail could be attributed to the combined characteristics of the phages as their wide host-range, the different lytic cycles, and other particularities described in this study. To our knowledge, there are some reports about the use of bacteriophages closest to those studied by us but mainly in food (e.g., Whichard et al., 2003; Zinno et al., 2014), and only few in animals (e.g., Hurley et al., 2008) although with uneven results.

\section{AUTHOR CONTRIBUTIONS}

$\mathrm{CB}$ and DS isolated and annotated the sequences the genomes of the three bacteriophages. JC carried out the final annotation, the characterization of the packaging process of the three bacteriophages, and the analysis of terminases. MS and JO participated in the characterization of the packaging process. PC and ML participated in the design and coordination of the study and in drafting the manuscript. All authors read and approved the final version of the manuscript.

\section{ACKNOWLEDGMENTS}

This work was supported by the Instituto Nacional de Investigación y Tecnología Agraria y Alimentaria; Ministerio de Ciencia e Innovación Español (RTA2006-00065), the Ministerio de Ciencia e Innovación de España (BFU2011-23478) and by the Generalitat de Catalunya (SGR2014/572). JC and JO are recipients of a predoctoral fellowship from the UAB. MS is the recipient of a fellowship from the Ministerio de Educación, Cultura y Deporte (COLAB 2014). CB was the recipient of a predoctoral fellowship from the Comissionat per a Universitats i Recerca del Departament d'Innovació, Universitats i Empresa de la Generalitat de Catalunya i del Fons Social Europeu. DS was supported by a predoctoral fellowship from CAPES (Coordenação de Aperfeiçoamento de Pessoal de Nível Superior). We are grateful to the Servei de Genòmica of the Universitat Autònoma de Barcelona (UAB) for their support.

\section{SUPPLEMENTARY MATERIAL}

The Supplementary Material for this article can be found online at: http://journal.frontiersin.org/article/10.3389/fmicb. 2016.00545 


\section{REFERENCES}

Abedon, S. T., Kuhl, S. J., Blasdel, B. G., and Kutter, E. M. (2011). Phage treatment of human infections. Bacteriophage 1, 66-85. doi: 10.4161/bact.1.2.15845

Altschul, S. F., Gish, W., Miller, W., Myers, E. W., and Lipman, D. J. (1990). Basic local alignment search tool. J. Mol. Biol. 215, 403-410. doi: 10.1016/S00222836(05)80360-2

Bailly-Bechet, M., Vergassola, M., and Rocha, E. (2007). Causes for the intriguing presence of tRNAs in phages. Genome Res. 17, 1486-1495. doi: $10.1101 /$ gr.6649807

Bardina, C. (2011). Estudio Sobre Terapia Fágica Contra S. enterica en Gallus gallus. Dissertation/master's thesis, Universitat Autònoma de Barcelona.

Bardina, C., Spricigo, D. A., Cortés, P., and Llagostera, M. (2012). Significance of the bacteriophage treatment schedule in reducing Salmonella colonization of poultry. Appl. Environ. Microbiol. 78, 6600-6607. doi: 10.1128/AEM.01257-12

Burch, L. H., Zhang, L., Chao, F. G., Xu, H., and Drake, J. W. (2011). The bacteriophage $\mathrm{T} 4$ rapid-lysis genes and their mutational proclivities. J. Bacteriol. 193, 3537-3545. doi: 10.1128/JB.00138-11

Casjens, S., and Thuman-Commike, P. (2011). Evolution of mosaic tailed bacteriophage genomes seen through the lens of phage P22 virion assembly. Virology 411, 393-415. doi: 10.1016/j.virol.2010.12.046

Casjens, S. R., and Gilcrease, E. B. (2009). Determining DNA packaging strategy by analysis of the termini of the chromosomes in tailed-bacteriophage virions. Methods Mol. Biol. 502, 91-111. doi: 10.1007/978-1-60327-565-1_7

Casjens, S. R., Gilcrease, E. B., Winn-Stapley, D. A., Schicklmaier, P., Schmieger, H., Pedulla, M. L., et al. (2005). The generalized transducing Salmonella Bacteriophage ES18: complete genome Sequence and DNA packaging strategy. J. Bacteriol. 187, 1091-1104. doi: 10.1128/JB.187.3.1091-11 04.2005

Center for Disease Control and Prevention (CDC) (2011). 2011 Estimates of Foodborne Illness in the United States (updated 15 April 2011). Atlanta: CDC. Available online at: http://www.cdc.gov/features/dsfoodborneestimates (Accessed April 24, 2013).

Chan, R. K., Botstein, D., Watanabe, T., and Ogata, Y. (1972). Specialized transduction of tetracycline resistance by phage P22 in Salmonella Typhimurium. II. Properties of a high-frequency-transducing lysate. Virology 50, 883-898. doi: 10.1016/0042-6822(72)90442-4

Colom, J., Cano-Sanabria, M., Otero, J., Cortés, P., Maspoch, D., and Llagostera, M. (2015). Liposome-encapsulated bacteriophages for enhanced oral phage therapy against Salmonella spp. Appl. Environ. Microbiol. 81, 4841-4849. doi: 10.1128/AEM.00812-15

Cortés, P., Spricigo, D. A., Bardina, C., and Llagostera, M. (2015). Remarkable diversity of Salmonella bacteriophages in swine and poultry. FEMS Microbiol. Lett. 362, 1-7. doi: 10.1093/femsle/fnu034

Darling, A. E., Mau, B., and Perna, N. T. (2010). ProgressiveMauve: multiple genome alignment with gene gain, loss and rearrangement. PLoS ONE 5:e11147. doi: 10.1371/journal.pone.0011147

Dobbins, A. T., Gerorge, M. Jr., Basham, D. A., Ford, M. E., Houtz, J. M., Pedulla, M. L., et al. (2004). Complete genomic sequence of the virulence Salmonella bacteriophage SP6. J. Bacteriol. 186, 1933-1944. doi: 10.1128/JB.186.7.19331944.2004

Endersen, L., O'Mahony, J., Hill, C., Ross, R. P., McAuliffe, O., and Coffey, A. (2014). Phage therapy in the food industry. Annu. Rev. Food Sci. Technol. 5, 327-349. doi: 10.1146/annurev-food-030713092415

Ermolaeva, M. D., Khalak, H. G., White, O., Smith, H. O., and Salzberg, S. L. (2000). Prediction of transcription terminators in bacterial genomes. J. Mol. Biol. 301, 27-33. doi: 10.1006/jmbi.2000.3836

European Food Safety Authority and European Centre for Disease Prevention and Control (2014). The European Union Summary Report on trends and sources of zoonoses, zoonotic agents and food-borne outbreaks in 2012. EFSA J. 12:3547. doi: $10.2903 /$ j.efsa.2014.3547

FARRP (Food allergy research and resource program) (2011). Lincoln, NE: University of Nebraska. Available online at: http://www.allergenonline.org (Accessed May 21, 2015)

Goodridge, L. D., and Bisha, B. (2011). Phage-based biocontrol strategies to reduce foodborne pathogens in foods. Bacteriophage 1, 130-137. doi: 10.4161/bact.1.3.17629
Grose, J. H., and Casjens, S. R. (2014). Understanding the enormous diversity of bacteriophages: the tailed phages that infect the bacterial family Enterobacteriaceae. Virology 468-470, 421-443. doi: 10.1016/j.virol.2014.08.024 Hendrix, R. W. (2002). Bacteriophages: evolution of the majority. Theor. Popul. Biol. 61, 471-480. doi: 10.1006/tpbi.2002.1590

Hurley, A., Maurer, J. J., and Lee, M. D. (2008). Using bacteriophages to modulate Salmonella colonization of the chicken's gastrointestinal tract: lessons learned from in silico and in vivo modeling. Avian Dis. 52, 599-607. doi: 10.1637/8288031808-Reg.1

Iwashita, S., and Kanegasaki, S. (1976). Enzymatic and molecular properties of base-plate parts of bacteriophage P22. Eur. J. Biochem. 65, 87-94. doi: 10.1111/j.1432-1033.1976.tb10392.x

Klumpp, J., Dorscht, J., Lurz, R., Bielmann, R., Wieland, M., Zimmer, M., et al. (2008). The terminally redundant, nonpermuted genome of Listeria bacteriophage A511: a model for the SPO1-like myoviruses of gram-positive bacteria. J. Bacteriol. 190, 5753-5765. doi: 10.1128/JB.00461-08

Klumpp, J., Fouts, D. E., and Sozhamannan, S. (2013). Bacteriophage functional genomics and its role in bacterial pathogen detection. Brief. Funct. Genomics 12, 354-365. doi: 10.1093/bfgp/elt009

Kropinski, A. M., Sulakvelidze, A., Konczy, P., and Poppe, C. (2007). Salmonella phages and prophages-genomics and practical aspects. Methods Mol. Biol. 394, 133-175. doi: 10.1007/978-1-59745-512-1_9

Lavigne, R., Seto, D., Mahdevan, P., Ackermann, H. W., and Kropinski, A. M. (2008). Unifying classical and molecular taxonomic classification: analysis of the Podoviridae using BLASTP-based tools. Res. Microbiol. 159, 406-414. doi: 10.1016/j.resmic.2008.03.005

Lowe, T. M., and Eddy, S. R. (1997). RNAscan-SE: a program for improved detection of transfer RNA genes in genomic sequence. Nucleic Acids Res. 25, 955-964. doi: 10.1093/nar/25.5.0955

Marti, R. (2013). Assembly of a Salmonella phage Cocktail with Broad, Strictly Virulent Activity and Detailed Characterization of the Phages Used. Dissertation/master's thesis. ETH Zurich.

McWilliam, H., Li, W., Uludag, M., Squizzato, S., Park, Y. M., Buso, N., et al. (2013). Analysis tool web services from the EMBL-EBI. Nucleic Acid Res. 41, W597-W600. doi: 10.1093/nar/gkt376

Miller, E. S., Kutter, E., Mosgi, G., Arisaka, F., Kunisawa, T., and Rüger, W. (2003). Bacteriophage T4 Genome. Microbiol. Mol. Biol. Rev. 67, 86-156. doi: 10.1128/MMBR.67.1.86-156.2003

Moreno Switt, A. I., Orsi, R. H., den Bakker, H. C., Vongkamjan, K., Altier, C., and Wiedmann, M. (2013). Genomic characterization provides new insight into Salmonella phage diversity. BMC Genomics. 14:481. doi: 10.1186/1471-2164$14-481$

Nguyen, A. H., Molineux, I. J., Springman, R., and Bull, J. J. (2012). Multiple genetic pathways to similar fitness limits during viral adaptation to a new host. Evolution 66, 363-374. doi: 10.1111/j.1558-5646.2011.01433.x

Nowicki, G., Barylski, J., Kujawa, N., and Gozdzicka-Józefiak, A. (2014). Complete genome sequence of Lelliottiapodophage phD2B. Genome Announc. 2:e0 1046-14.

Oliveira, H. O., Melo, L. D. R., Santos, S. B., Nóbrega, F. L., Cerca, N., Azeredo, J., et al. (2013). Molecular aspects and comparative genomics of bacteriophage endolysins. J.Virol. 87, 4558-4570. doi: 10.1128/JVI.03277-12

Poteete, A. R., Fenton, A. C., and Murphy, K. C. (1988). Modulation of Escherichia coli RecBCD activity by the bacteriophage lambda Gam and P22 Abc functions. J. Bacteriol. 170, 2012-2021.

Sambrook, J., Fritsch, E. F., and Maniatis, T. (1989). Molecular Cloning a Laboratory Manual. Long Island, NY: Cold Spring Harbor Laboratory Press.

Scholl, D., Kieleczawa, J., Kemp, P., Rush, J., Richardson, C. C., Merril, C., et al. (2004). Genomic analysis of bacteriophages SP6 and K1-5, an estranged subgroup of the T7 supergroup. J. Mol. Biol. 335, 1151-1171. doi: 10.1016/j.jmb.2003.11.035

Scholl, D., and Merril, C. (2005). The genome of bacteriophage K1F, a T7like phage that has acquired the ability to replicate on K1 strains of Escherichia coli. J. Bacteriol. 187, 8499-8503. doi: 10.1128/JB.187.24.8499-85 03.2005

Shine, J., and Dalgarno, L. (1974). The 3'-terminal sequence of Escherichia coli 16S rRNA: complementarity of nonsense triplets and ribosome binding sites. Proc. Natl. Acad. Sci. U.S.A. 71, 1342-1346. doi: 10.1073/pnas.71. 4.1342 
Smith-Mungo, L., Chan, I. T., and Landy, A. (1994). Structure of the P22 att site. Conservation and divergence in the lambda motif of recombinogenic complexes. J. Biol. Chem. 269, 20798-20805.

Solovyev, V., and Salamov, A. (2011). "Automatic annotation of microbial genomes and metagenomic sequences," in Metagenomics and Its Applications in Agriculture, Biomedicine and Environmental Studies, ed R. W. Li (Hauppauge, NY: Nova Science Publishers), 61-78.

Spricigo, D. (2011). La Desinfección Basada En Bacteriófagos Como Herramienta de Biocontrol de Salmonella en Alimentos. Dissertation/master's thesis, Universitat Autònoma de Barcelona.

Spricigo, D. A., Bardina, C., Cortés, P., and Llagostera, M. (2013). Use of a bacteriophage cocktail to control Salmonella in food and the food industry. Int. J. Food Microbiol. 165, 169-174. doi: 10.1016/j.ijfoodmicro.2013.05.009

Sulakvelidze, A. (2011). Safety by nature: potential bacteriophage applications. Microbe 6, 122-126. doi: 10.1128/microbe.6.122.1

Susskind, M. M., and Botstein, D. (1978). Molecular genetics of bacteriophage P22. Microbiol. Rev. 42, 385-413.

Tamura, K., Stecher, G., Peterson, D., Filipski, A., and Kumar, S. (2013). MEGA6: molecular evolutionary genetics analysis version 6.0. Mol. Biol. Evol. 30, 2725-2729. doi: 10.1093/molbev/mst197

Thomson, N., Baker, S., and Pickard, D. (2004). The role of prophage-like elements in the diversity of Salmonella enterica serovars. J. Mol. Biol. 339, 279-280. doi: 10.1016/j.jmb.2004.03.058

Turner, D., Reynolds, D., Seto, D., and Mahdevan, P. (2013). CoreGenes3.5: a webserver for the determination of core genes from sets of viral and small bacterial genomes. BMC Res. Notes 6:140. doi: 10.1186/1756-05006-140
Vander Byl, C., and Kropinski, A. M. (2000). Sequence of the genome of Salmonella bacteriophage P22. J. Bacteriol. 182, 6472-6481. doi: 10.1128/JB.182.22.64726481.2000

Whichard, J. M., Sriranganathan., N., and Pierson, F. W. (2003). Suppression of Salmonella growth by wild-type and large-plaque variants of bacteriophage Felix O1 in liquid culture and on chicken frankfurters. J. Food Prot. 66, 220-225.

Whichard, J. M., Weigt, L. A., Borris, D. J., Li, L. L., Zhang, Q., Kapur, V., et al. (2010). Complete genomic sequence of bacteriophage Felix O1. Viruses 2, 710-730. doi: 10.3390/v2030710

Wu, H., Sampson, L., Parr, R., and Casjens, S. (2002). The DNA site utilized by bacteriophage P22 for initiation of DNA packaging. Mol. Microbiol. 45, 1631-1646. doi: 10.1046/j.1365-2958.2002.03114.x

Zinno, P., Devirgiliis, C., Ercolini, D., Ongeng, D., and Mauriello, G. (2014). Bacteriophage P22 to challenge Salmonella in foods. Int. J. Food Microbiol. 91, 64-71. doi: 10.1016/j.ijfoodmicro.2014.08.037

Conflict of Interest Statement: The authors declare that the research was conducted in the absence of any commercial or financial relationships that could be construed as a potential conflict of interest.

Copyright (c) 2016 Bardina, Colom, Spricigo, Otero, Sánchez-Osuna, Cortés and Llagostera. This is an open-access article distributed under the terms of the Creative Commons Attribution License (CC BY). The use, distribution or reproduction in other forums is permitted, provided the original author(s) or licensor are credited and that the original publication in this journal is cited, in accordance with accepted academic practice. No use, distribution or reproduction is permitted which does not comply with these terms. 